\title{
Imprecise knowledge based design and development of titanium alloys for prosthetic applications
}

\author{
S. Datta ${ }^{1^{*}}$ and M. Mahfouf ${ }^{2}$, Q. Zhang ${ }^{3}$, P.P. Chattopadhyay ${ }^{4}$, N. Sultana ${ }^{5}$ \\ ${ }^{1}$ B.U. Institute of Engineering \\ Bankura 722146, India \\ ${ }^{2}$ Department of Automatic Control and Systems Engineering \\ The University of Sheffield \\ Sheffield S1 3JD, UK \\ ${ }^{3}$ School of Engineering and Digital Arts \\ University of Kent \\ Canterbury CT2 7NT, UK \\ ${ }^{4}$ National Institute of Foundry and Forge Technology \\ Hatia 834003, Ranchi, India \\ ${ }^{5}$ School of Materials Science and Engineering \\ Indian Institute of Engineering Science and Technology, Shibpur \\ Howrah 711103, India \\ *Corresponding author, Email: shu.datt@gmail.com, Phone: +91 3242259360
}

\begin{abstract}
Imprecise knowledge on the composition-processing-microstructure-property correlation of titanium alloys combined with experimental data are used for developing rule based models for predicting the strength and elastic modulus of titanium alloys. The developed models are used for designing alloys suitable for orthopaedic and dental applications. Reduced Space Searching Algorithm is employed for the multi-objective optimization to find composition, processing and microstructure of titanium alloys suitable for orthopaedic applications. The conflicting requirements attributes of the alloys for this particular purpose are high strength with low elastic modulus, along with adequate biocompatibility and low costs. The 'Pareto' solutions developed through multi-objective optimization show that the preferred compositions for the fulfilling the above objectives lead to $\beta$ or near $\beta$ alloys. The concept of decision making employed on the solutions leads to some compositions, which should provide better combination of the required attributes. The experimental development of some of the alloys has been carried out as guided by the model-based design methodology
\end{abstract}


(C2015. This manuscript version is made available under the CC-BY-NC-ND 4.0 license http://creativecommons.org/licenses/by-nc-nd/4.0/

presented in this research. Primary characterizations of the alloys show encouraging results in terms of the mechanical properties.

Keywords: titanium alloy, orthopaedic application, alloy design, rule based modelling, evolutionary algorithm, multi-objective optimization.

\section{Introduction:}

The metallic biomaterials are considered the most suitable for replacing failed hard tissues, and among them titanium alloys are getting much attention due to excellent specific strength and the best biocompatibility. Pure titanium and Ti-6Al-4V still occupy most of the market of titanium biomaterials $[1,2]$. But due to lower elastic modulus, $\beta$ type titanium alloys are found advantageous from the point of mechanical biocompatibility, regarded as an important factor. This property is important as a low elastic modulus reduces stress shielding of the neighbouring bone [3-5]. But pure $\mathrm{Ti}$ and $\alpha+\beta$ type Ti-6Al-4V alloys have an elastic modulus of 105-110 GPa, while the human cortical bone has a stiffness of around $20 \mathrm{GPa}$ [6, 7]. $\beta$ or near- $\beta$ alloys include $\mathrm{Mo}, \mathrm{Nb}, \mathrm{Zr}, \mathrm{Fe}, \mathrm{Ta}, \mathrm{Pd}$ and $\mathrm{Sn}$ as alloying elements $[8,9]$. The implant materials also need high fatigue strength in addition to the low elastic modulus and high strength. Therefore, alloying elements such as $\mathrm{Cu}, \mathrm{Co}, \mathrm{Ni}$, and $\mathrm{Si}$ are used for the purpose of strengthening [10]. The $\beta$-phase being highly plastic, forming of $\beta$-Ti-alloys becomes easy [11]. In addition, some recent concern has been highlighted over the use of Ti$6 \mathrm{Al}-4 \mathrm{~V}$, as it seems that $\mathrm{Al}$ and $\mathrm{V}$ dissolve out inside human body and may have a negative effect on the body. Thus, substitution of $\mathrm{V}$ by $\mathrm{Nb}$ or Ta, and substitution of $\mathrm{Al}$ by $\mathrm{Zr}$ can be advantageous from this aspect also [12-14].

It seems from the above that a judicious selection of composition may lead to further improvement of the properties of the Ti alloys suitable for its use as an implant material. Thus the information generated by previous workers through experimental findings $[1,3,15$ 18] are utilized in this research in addition to the prior knowledge of the system to find the optimum composition of Ti alloys to achieve the best combination of high strength, low elastic modulus, adequate biocompatibility and with low costs. But searching the optimum combination of the alloying additions in the experimental domain becomes expensive from the view point of time and money. On the other hand computational design strategies have the capacity to stimulate 'right first time' experimentation $[19,20]$, which aims to achieve the targeted properties within a few attempts. The 'first principle' techniques are utilized by several workers using parameter-free density functional theory calculations to provide 
(C2015. This manuscript version is made available under the CC-BY-NC-ND 4.0 license http://creativecommons.org/licenses/by-nc-nd/4.0/

guidance in selecting and optimizing $\mathrm{Ti}$ alloys with respect to the use of non-toxic alloy elements, the stabilization of the $\beta$-phase and the reduction of the stiffness compared [21] or by means of ab initio plane-wave pseudo-potential method to investigate mono-vacancy, divacancy and self-interstitials in $\alpha$ titanium [22]. There are several attempts to develop composition-property correlation in other materials also, e.g. single crystal elastic constants of $\mathrm{Mg}-\mathrm{Li}$ alloys using density functional theory (DFT) [23], semiconductor spintronics [24], and $\mathrm{Pb}(\mathrm{Sc} 0.5 \mathrm{Nb} 0.5) \mathrm{O} 3$ perovskite alloy [25] etc. However, informatics- based design using computational intelligence techniques have been successfully used for designing Ti alloys [26-27] and other materials [28-30]. Informatics based materials design strategies try to extract the inherent correlation within data and utilize the information for designing novel materials [31]. Statistical as well as computational intelligence based techniques have the capacity to use data as well as imprecise knowledge (expert-knowledge) of a system and derive a model of the system that has the capability to generalise behaviour over a wide range of parameter variability. It can thus successfully and specifically handle noise as well as uncertainties in complex materials systems [32]- Such techniques are known to be 'universal approximators'. Such efforts ultimately reinforce the 'first principle' approaches of materials modelling and design. In this work models for yield strength and elastic modulus of Ti alloys are developed using an innovative two-layered fuzzy inference system (FIS), where the first layered correlating the composition and process variables with the microstructural features is developed using prior-knowledge, and the second layer correlating the microstructure with properties were developed using published experimental data. An fuzzy inference system is a modelling tool based on fuzzy logic [33], which can be defined as an extension of multivalued logic. It has its origin in the theory of fuzzy sets, a theory which relates to classes of objects with transitional boundaries in which a membership of the set is a matter of 'degree.' FIS can use imprecise knowledge of a system in the form of if-then rules to map the relationship between inputs and outputs [34]. Fuzzy logic can also be used to develop if-then rules from experimental data, which can be used to develop the model. Such models can extract useful knowledge about the system, particularly that relating the microstructural features with the properties, in the form of if-then statements. The developed models are then used for identifying optimal combinations of compositions and processing for high strength and low elastic modulus. The objectives being conflicting in nature, multi-objective optimization is employed using an evolutionary algorithm known as Reduced Space Searching Algorithm (RSSA) [35, 36]. Evolutionary algorithm is a term used to describe 
(C2015. This manuscript version is made available under the CC-BY-NC-ND 4.0 license http://creativecommons.org/licenses/by-nc-nd/4.0/

computer based problem solving systems which use computational models of evolutionary processes as key elements in their design and implementation [37]. RSSA is one type of evolutionary algorithm that is inspired by humans' natural searching behaviour. To seek a target within a large and complex search space, a general means to reducing the workload could be of dividing the search space into parts and strategically arranging the sequence and density of searching among the various subspaces, as shown in Fig. 1. RSSA employs such an idea hierarchically and repeatedly so as to achieve the fast convergence and accurate optimization.

It is worth noting that the biocompatibility issue is treated as a constraint in the optimization process. For costs a weighted summation model of the elemental constituent is developed with the recent cost of the alloying additions. In case of multi-objective optimization, unlike the single objective optimization, a set of non-dominated solutions, where each solution is better than other in at least one objective, evolve; this set of solutions is called Pareto solutions [38-40]. In the present study, the compositions of alloys selected from the evolved Pareto solutions are developed for experimental trials.

\section{Database}

The published experimental data are collected from various sources [1, 41-50]. The input variables consist of compositional variables and processing parameters and the output variable are the mechanical properties. For strength, the number of training data is 145 and the number of testing data is 26 , and for elastic modulus, the number of training data is 165 and the number of testing data is 29 . The list of input and output variables, with their minimum and maximum values, is presented in Table 1.

\section{Fuzzy Model Development}

A Fuzzy Inference System (FIS) that maps an input space into an output space using the theory of fuzzy logic $[33,34]$ is used in this work. The FIS has three parts, viz. fuzzy membership functions, fuzzy operators and specific implication operations in the form of ifthen statements or rules to give a quantitative meaning to a qualitative (linguistic) phrase (statement). The membership function of a fuzzy set represents the degree of truth, where fuzzy truth represents membership in vaguely defined sets. The fuzzy operators are the familiar operators like AND, OR, and NOT, can expressed as intersection, union, and complement. This non-linear mapping is capable of dealing with ambiguities (uncertainties) 
(C2015. This manuscript version is made available under the CC-BY-NC-ND 4.0 license http://creativecommons.org/licenses/by-nc-nd/4.0/

surrounding the real'-world and is also able to deal with what is known as 'the curse of dimensionality'. A sample fuzzy rule can be expressed as follows:

If $\mathrm{P}$ is $\mathrm{X}$ and $\mathrm{Q}$ is $\mathrm{Y}$ then $\mathrm{R}$ is $\mathrm{Z}$

where $\mathrm{X}, \mathrm{Y}$ and $\mathrm{Z}$ are linguistic variables (labels) defined by fuzzy sets on the specific ranges e.g. high, low, fast slow etc., while $\mathrm{P}$ and $\mathrm{Q}$ are the input variables, and $\mathrm{R}$ is the output variable. In such rules the 'if' part is called the "antecedent" and the 'then' part is called the "consequent". In the above fuzzy rule, the inputs and outputs would be both represented by fuzzy sets in case of Mamdani-type representation [34]. The FIS is explained in Fig. 2. As the Mamdani-type FIS is used in the present work, other type of FISs are not discussed.

In this work, predefined fuzzy sets are generated using the knowledge of experts (the authors). The rule-bases for the first layer of the models, i.e. the rules correlating the composition and microstructural features, are developed from prior knowledge. In case of the second layer correlating the microstructural features to the mechanical properties, the primary work consists of generating appropriate fuzzy rule-base. Any redundancy of the fuzzy rule is estimated via the following 'confidence' measure [51]:

$$
\operatorname{conf}(\mathbf{A} \rightarrow B)=\frac{|C(\mathbf{A}) \times C(B)|}{|C(\mathbf{A})|}=\frac{\sum_{n=1}^{m}\left(\mathrm{~N}_{\mathbf{A}}\left(\mathbf{x}_{n}\right) \times \mu_{B}\left(y_{n}\right)\right)}{\sum_{n=1}^{m} \mathrm{~N}_{\mathbf{A}}\left(\mathbf{x}_{n}\right)}
$$

where $|C(A) \times C(B)|$ is the number of training patterns compatible to the antecedent (the 'if' part of the rule) $\boldsymbol{A}$ and the consequent (the 'then' part of the rule) $B$, whereas $|C(\boldsymbol{A})|$ is the same for the antecedent $\boldsymbol{A}$ only. $\mathrm{N}_{\boldsymbol{A}}\left(\boldsymbol{x}_{n}\right)$ is the grade of compatibility of the input $\boldsymbol{x}_{n}$ along with antecedent $\boldsymbol{A}=\left[A_{1}, A_{2}, \ldots, A_{i}\right]^{\mathrm{T}}$, and $\mu_{B}\left(y_{n}\right)$ is that of the output value $y_{n}$ with the consequent $B . \mathrm{N}_{\boldsymbol{A}}\left(\boldsymbol{x}_{n}\right)$ is defined by the minimum or the product operator, such that:

$$
\mathrm{N}_{A}\left(\mathbf{x}_{n}\right)=\min \left(\mu_{A_{1 j}}\left(x_{1 n}\right), \mu_{A_{2 j}}\left(x_{2 n}\right), \ldots, \mu_{A_{j j}}\left(x_{i n}\right)\right)
$$

or

$\mathrm{N}_{A}\left(\boldsymbol{x}_{n}\right)=\mu_{A_{1 j}}\left(x_{1 n}\right) \times \mu_{A_{2 j}}\left(x_{2 n}\right) \times \ldots \times \mu_{A_{i j}}\left(x_{i n}\right)$

In this case, to reduce the complexity of the system, and for the ease of expressing the existing domain knowledge in the form of if-then rules, the number of inputs is reduced from fourteen (14) to nine (9), using Mo-equivalent [10], where,

Mo-equivalent $=\mathrm{Mo}+0.6 * \mathrm{~V}+0.28 * \mathrm{Nb}+0.22 * \mathrm{Ta}+1.25 * \mathrm{Cr}+2.5 * \mathrm{Fe}$ 
(C2015. This manuscript version is made available under the CC-BY-NC-ND 4.0 license http://creativecommons.org/licenses/by-nc-nd/4.0/

Thus, the nine variables used for modelling are Mo-equivalent, Al, $\mathrm{Zr}$, Sn, deformation temperature, solutionising temperature, cooling rate, ageing temperature and ageing time. Two separate models are developed for two outputs, i.e. yield strength (YS) and elastic modulus (EM), as per the schematics shown in Fig. 3.

Six Mamdani FISs correlating the composition and process variables with microstructural features are developed using prior knowledge of the system. Two Mamdani FISs correlating the microstructural features with the properties is developed using the database generated from published literatures.

\subsection{FIS for volume fraction of $\beta$}

Among the alloy additions most of the elements are $\beta$ stabilizers, whose individual effects are combined in the form of Mo equivalent [41]. Al is $\alpha$ stabilizer. Higher solutionising temperature and faster cooling rate leads to higher volume fraction of $\beta$. This concept is utilized to develop the rule base for this FIS. The rules are as follows:

1. If (Mo equivalent is high) and ( $\mathrm{Al}$ content is low) and (Solutionising temp is high) and (Cooling rate is fast) then (volume fraction of $\beta$ is high)

2. If (Mo equivalent is low) and ( $\mathrm{Al}$ content is high) and (Solutionising temp is low) and (Cooling rate is slow) then (volume fraction of $\beta$ is low)

3. If (Mo equivalent is low) and (Al content is high) and (Solutionising temp is medium) and (Cooling rate is moderate) then (volume fraction of $\beta$ is low)

4. If (Mo equivalent is medium) and (Al content is medium) and (Solutionising temp is medium) and (Cooling rate is moderate) then (volume fraction of $\beta$ is medium)

5. If (Mo equivalent is high) and (Al content is medium) and (Solutionising temp is high) and (Cooling rate is moderate) then (volume fraction of $\beta$ is medium)

6. If (Mo equivalent is high) and ( $\mathrm{Al}$ content is low) and (Solutionising temp is high) and (Cooling rate is moderate) then (volume fraction of $\beta$ is high)

The surface view genrated by the developed FIS shows how much prior imprecise knowledge the model can capture (Fig. 4).

\subsection{FIS for solid solution hardening}

Here, the variation of hardness due to addition of alloying elements, found by previous workers [52], is considered to create the rule base as well as to fix the scale. Among the 
(C2015. This manuscript version is made available under the CC-BY-NC-ND 4.0 license http://creativecommons.org/licenses/by-nc-nd/4.0/

alloying elements the purpose of adding $\mathrm{Zr}$ is chiefly due to its solid solution hardening, as it is a neutral element from the point of phase stabilization [10]. Other than that, Al, Sn and all other alloying additions ( $\beta$ stabilizers) have some effect on the final properties. All these effects are summarized in the form of if-then rules. The role of the $\beta$ stabilizers is described in the form of Mo equivalent. The effect of solid solution hardening is expressed in terms of Hardness (soln) (VHN). The rules generated for the FIS are as follows:

1. If (Mo equivalent is high) and ( $\mathrm{Al}$ content is high) and ( $\mathrm{Zr}$ content is high) and ( $\mathrm{Sn}$ content is high) then (solution hardening is high)

2. If (Mo equivalent is low) and ( $\mathrm{Al}$ content is low) and ( $\mathrm{Zr}$ content is low) and ( $\mathrm{Sn}$ content is low) then (solution hardnes is low)

3. If (Mo equivalent is high) and ( $\mathrm{Al}$ content is high) and ( $\mathrm{rr}$ content is medium) and ( $\mathrm{Sn}$ content is medium) then (solution hardness is medium)

4. If (Mo equivalent is medium) and ( $\mathrm{Al}$ content is medium) and ( $\mathrm{Zr}$ content is low) and (Sn content is low) then (solution hardnes is low)

5. If (Mo equivalent is high) and ( $\mathrm{Al}$ content is medium) and ( $\mathrm{Zr}$ content is high) and ( $\mathrm{Sn}$ content is high) then (solution hardness is high)

The surface views of the FIS are shown in Fig. 5.

\section{FIS: Grain size}

Most of the $\beta$ stabilizers act as grain refiners, by increasing the recrystallisation temperature. Hence, the Mo equivalent was used as a qualitative expression for the grain refinement due to alloying addition. Daisuke Kuroda et al. observed that the average grain size of the alloys varies with varying amounts of $\mathrm{Mo}, \mathrm{Nb}, \mathrm{Zr}$, Sn and other alloying elements [11,53]. A lower deformation temperature increases the grain refinement as well as defects in the structure. A lower solution temperature reduces the possibility of grain growth. These factors are expressed in terms of fuzzy if-then rules as follows:

1. If (Mo equivalent is low) and (Deformation temperature is high) and (Solutionising temperature is high) then (grain size is high)

2. If (Mo equivalent is high) and (Deformation temperature is low) and (Solutionising temperature is low) then (grain size is low)

3. If (Mo equivalent is medium) and (Deformation temperature is medium) and (Solutionising temperature is medium) then (grain size is medium) 
(C2015. This manuscript version is made available under the CC-BY-NC-ND 4.0 license http://creativecommons.org/licenses/by-nc-nd/4.0/

4. If (Mo equivalent is low) and (Deformation temperature is low) and (Solutionising temperature is low) then (grain size is medium)

5. If (Mo equivalent is medium) and (Deformation temperature is low) and (Solutionising temperature is low) then (grain size is low)

The surfaced generated from the FIS prediction are shown in Fig. 6.

\section{FIS: Acicularity}

The acicularity of microstructure has significant effect on the mechanical properties of the Ti alloys. The acicular structures may form due to transformation at low temperature (martensite formation) or due to formation of Wüdmanstatten structure. Though unlike steel, martensites in $\mathrm{Ti}$ alloys are not strong, this factor was incorporated in the microstructure to explain its specific role in strength and elastic modulus. Filip et al. [54] noticed that the thickness and length of the $\alpha$-phase decrease with increasing cooling rate and with increasing content of the $\beta$-stabilising elements. Acicularity is expressed here in terms of average aspect ratio of the grains. The rules generated from the concept of physical metallurgy of Ti alloys are as follows:

1. If (Mo equivalent is high) and ( $\mathrm{Zr}$ content is low) and ( $\mathrm{Sn}$ content is low) and (solutionising temperature is high) and (Cooling rate is fast) then (aspect ratio is high)

2. If (Mo equivalent is low) and ( $\mathrm{Zr}$ content is low) and ( $\mathrm{Sn}$ content is low) and solutionising temperature is high) and (Cooling rate is slow) then (aspect ratio is high)

3. If (Mo equivalent is high) and ( $\mathrm{Zr}$ content is high) and ( $\mathrm{Sn}$ content is high) then (aspect ratio is low)

4. If (Mo equivalent is low) and ( $\mathrm{Zr}$ content is low) and ( $\mathrm{Sn}$ content is low) and (solutionising temperature is low) and (Cooling rate is slow) then (aspect ratio is low)

5. If (Mo equivalent is medium) and ( $\mathrm{rr}$ content is medium) and ( $\mathrm{Sn}$ content is medium) and (solutionising temperature is medium) and (Cooling rate is moderate) then (aspect ratio is medium)

Fig. 7 shows the surfaces generated by the FIS.

\section{FIS: Defect in the microstructure}

Defect in the structure is generally shown through the dislocation density. A higher density of dislocation is generated by deformation below the recrystallisation temperature, lower 
(C2015. This manuscript version is made available under the CC-BY-NC-ND 4.0 license http://creativecommons.org/licenses/by-nc-nd/4.0/

solutionising temperature and faster cooling. Here the concepts used are not specific to Ti alloys. The rules for this FIS are as follows:

1. If (Deformation temperature is low) and (solutionising temperature is low) and (Cooling rate is fast) then (dislocation density is high)

2. If (Deformation temperature is high) and (solutionising temperature is high) and (Cooling rate is slow) then (dislocation density is low)

3. If (Deformation temperature is medium) and (solutionising temperature is medium) and (Cooling rate is moderate) then (dislocation density is medium)

4. If (Deformation temperature is low) and (solutionising temperature is medium) and (Cooling rate is slow) then (dislocation density is low)

The surface views generated as shown in Fig. 8.

\section{FIS: Other decomposition products}

The solutionised alloy, when aged, forms several types of intermetallics as precipitates within the matrix; this leads to precipitation hardening. Ageing at $350^{\circ} \mathrm{C}$ hard and brittle $\omega$ phase precipitates in a dispersive manner, which leads to the significant increase of elastic modulus along with decrease of plasticity $[10,52]$. But when the alloy is aged above $350^{\circ} \mathrm{C}$ the $\omega$ precipitation is reduced with the appearance of dot $\alpha$ precipitation, which decrease elastic modulus and strength and increase plasticity. Here, it is expressed in terms of Hardness (pptn) (VHN). A method similar to that employed in the case of solid solution hardening is employed here also. The formulated fuzzy rules are as follows:

1. If (Mo equivalent is medium) and (Solutionising temp is high) and (Cooling rate is fast) and (Ageing temp is medium) and (Ageing time is medium) then (hardness_pptn is high)

2. If (Mo equivalent is high) and (Solutionising temp is medium) and (Cooling rate is fast) and (Ageing temp is high) and (Ageing time is high) then (hardness pptn is high)

3. If (Mo equivalent is low) and (Solutionising temp is low) and (Cooling rate is slow) and (Ageing temp is low) and (Ageing time is low) then (hardness pptn is low)

4. If (Mo equivalent is high) and (Solutionising temp is high) and (Cooling rate is slow) and (Ageing temp is low) and (Ageing time is low) then (hardness pptn is low) 
(C2015. This manuscript version is made available under the CC-BY-NC-ND 4.0 license http://creativecommons.org/licenses/by-nc-nd/4.0/

5. If (Mo equivalent is medium) and (Solutionising temp is medium) and (Cooling rate is moderate) and (Ageing temp is high) and (Ageing time is high) then (hardness_pptn is medium)

The surface views describes the effects of the variables on precipitation hardening, as depicted by the rule based FIS (Fig. 9).

The first part of the model, correlating the composition and process variables with the microstructural features, is generated from prior knowledge as described above. This model consisting of six FISs is same for both models, i.e. models for yield strength and elastic modulus. The second part of the models is generated separately using data collected from several published literatures as stated above. Here, the FIS is generated through rules which are evolved using the error minimization for predicting the existing database using all possible rule sets. The optimization uses the Reduced Space Searching Algorithm (RSSA) $[35,36]$; this algorithm is a nature-inspired search technique which aims to shift the search space to a subspace including the 'optimum'. In this technique, no equations (e.g. derivativebased equations) or evolutionary operators (such as mutation and crossover) are used, thus creating the opportunity to integrate this idea with other optimization techniques. This algorithm has already been successfully validated by a number of industrial applications [36]. The rules, generated in this process for the two FISs correlating the microstructure with two properties, can be used for knowledge elicitation, since the correlation between microstructure and mechanical properties, particularly in case of elastic modulus, is not clearly known.

\section{FIS: Yield Strength}

As stated above the rules relating the microstructural features and the YS for Ti alloys are extracted from the database using optimization technique. The rules generated from the minimization of the error for predicting the existing database are as follows:

1. If (volume fraction of $\beta$ is low) and (solution hardening is low) and (grain size is low) and (acicularity is high) and (dislocation density is high) and (decomposition product is low) then (Yield Strength is high)

2. If (volume fraction of $\beta$ is low) and (solution hardening is medium) and (grain size is medium) and (dislocation density is high) and (decomposition product is medium) then (Yield Strength is high) 
(C2015. This manuscript version is made available under the CC-BY-NC-ND 4.0 license http://creativecommons.org/licenses/by-nc-nd/4.0/

3. If (solution hardening is medium) and (grain size is low) and (acicularity is high) and (dislocation density is high) and (decomposition product is medium) then (Yield Strength is medium)

4. If (solution hardening is medium) and (acicularity is medium) and (dislocation density is high) and (decomposition product is low) then (Yield Strength is low -medium)

5. If (volume fraction of $\beta$ is medium) and (solution hardening is medium) and (grain size is high) and (acicularity is low) and (dislocation density is low) then (Yield Strength is highmedium)

6. If (volume fraction of $\beta$ is medium) and (grain size is high) and (acicularity is low) and (dislocation density is high) and (decomposition product is low) then (Yield Strength is high-medium)

7. If (volume fraction of $\beta$ is low) and (grain size is high) and (dislocation density is medium) then (Yield Strength is low)

8. If (volume fraction of $\beta$ is low) and (solution hardening is medium) and (grain size is high) and (dislocation density is low) and (decomposition product is high) then (Yield Strength is low-medium)

9. If (volume fraction of $\beta$ is low) and (solution hardening is medium) and (grain size is high) and (acicularity is medium) and (decomposition product is high) then (Yield Strength is medium)

10. If (solution strength is high) and (grain size is low) and (acicularity is high) and (dislocation density is low) and (decomposition product is high) then (Yield Strength is high-medium)

11. If (volume fraction of $\beta$ is low) and (grain size is medium) and (acicularity is high) and (dislocation density is medium) and (decomposition product is high) then (Yield Strength is low-medium)

12. If (volume fraction of $\beta$ is medium) and (solution hardening is low) and (grain size is high) and (acicularity is low) and (dislocation density is low) then (Yield Strength is high)

13. If (volume fraction of $\beta$ is low) and (solution hardening is low) and (grain size is high) and (acicularity is high) then (Yield Strength is medium)

14. If (volume fraction of $\beta$ is low) and (solution hardening is low) and (grain size is medium) and (decomposition product is high) then (Yield Strength is high-medium) 
(C2015. This manuscript version is made available under the CC-BY-NC-ND 4.0 license http://creativecommons.org/licenses/by-nc-nd/4.0/

15. If (volume fraction $\beta$ is high) and (solution hardening is medium) and (grain size is low) and (dislocation density is high) and (decomposition product is low) then (Yield Strength is low)

The high number of elicited rules indicates the complexity of the system. But this also makes it difficult to understand the correlation described through the linguistic expressions. Still an in-depth study of the rules shows that higher amount of $\beta$ reduces the strength. But it is difficult to understand the complex contribution of decomposition products of $\beta$, developed through ageing. It is worth noting here that the $\beta$ grains may contain $\alpha, \alpha^{\prime \prime}$ and $\omega$ phases, depending on the composition and processing [10]. But the roles of these phases vary significantly on the final property of the alloy. On the one hand the, $\alpha$ and $\omega$ phases increase the strength and elastic modulus, with the effect of $\omega$ more profound than the other one. On the other hand $\alpha^{\prime \prime}$ has the reverse such a role. Thus it becomes difficult for the rules to capture the phenomena in a simpler way. A similar complexity exists in case of solution hardening, grain size and defects in microstructure. The real relations are better revealed by the surface plots developed from the FIS guided by the above rules, which are reported later. The model predictions for the existing data are shown in Fig. 10. The excellent predictability of the novel semi-empirical model developed using imprecise knowledge as well as data shows that how imprecise knowledge of a materials system could be utilised to develop a predictive model.

The surface views generated by the model are shown in Fig. 11. Here, it can be seen that the effect of volume fraction of $\beta$ has been clearly depicted by the model prediction, but effect of grain size is not that significant. In case of solid solution hardening it can be seen that initially the strength is increased, but then it diminishes (Fig. 11b). This may be due to fact that here most of the alloying additions are $\beta$ stabilizers, and achieving higher solution hardening means a higher alloying addition, which leads to increase in $\beta$ content. This in turn leads to a decrease in strength. The effect of precipitates is not profound at low solution hardening, i.e. in the low alloying addition regime, i.e. in the $\alpha$ phase. But the situation becomes complex in the $\beta$ phase domain. The role of defects seems to be not so significant (Fig. 11c). In the case of a data base where cold deformation is missing, and mostly there exists some post deformation heat treatment, such behaviour is expected. The role of aspect ratio is rather complex and it can be seen that in the medium level it leads to softening. 
(C2015. This manuscript version is made available under the CC-BY-NC-ND 4.0 license http://creativecommons.org/licenses/by-nc-nd/4.0/

\section{FIS: Elastic Modulus}

The rules for the elastic modulus model are elicited using the same method as for the yield strength model, and are as follows:

1. If (volume fraction of $\beta$ is low) and (solution hardening is medium) and (grain size is low) and (acicularity is medium) and (dislocation density is high) and (decomposition product is high) then (Elastic Modulus is low)

2. If (solution strength is high) and (grain size is medium) and (acicularity is high) and (dislocation density is low) and (decomposition product is low) then (Elastic Modulus is medium)

3. If (volume fraction of $\beta$ is high) and (solution hardening is low) and (grain size is low) and (acicularity is high) and (dislocation density is low) and (decomposition product is low) then (Elastic Modulus is low)

4. If (grain size is low) and (acicularity is high) and (dislocation density is low) and (decomposition product is low) then (Elastic Modulus is low-medium)

5. If (volume fraction of $\beta$ is medium) and (solution hardening is low) and (grain size is medium) and (acicularity is low) and (decomposition product is medium) then (Elastic Modulus is high-medium)

6. If (volume fraction of $\beta$ is high) and (solution hardening is low) and (grain size is high) and (acicularity is high) and (dislocation density is high) and (decomposition product is high) then (Elastic Modulus is medium)

7. If (volume fraction of $\beta$ is medium) and (solution hardening is low) and (grain size is high) and (dislocation density is medium) then (Elastic Modulus is medium)

8. If (volume fraction of $\beta$ is low) and (grain size is medium) and (acicularity is low) and (dislocation density is low) and (decomposition product is low) then (Elastic Modulus is low)

9. If (volume fraction of $\beta$ is low) and (solution hardening is medium) and (acicularity is medium) and (decomposition product is low) then (Elastic Modulus is high)

10. If (volume fraction of $\beta$ is low) and (solution hardening is medium) and (grain size is high) and (acicularity is medium) and (dislocation density is high) and (decomposition product is high) then (Elastic Modulus is low)

11. If (volume fraction of $\beta$ is low) and (solution hardening is low) and (grain size is high) and (acicularity is low) and (dislocation density is high) and (decomposition product is high) then (Elastic Modulus is high-medium) 
(C2015. This manuscript version is made available under the CC-BY-NC-ND 4.0 license http://creativecommons.org/licenses/by-nc-nd/4.0/

12. If (volume fraction of $\beta$ is low) and (solution hardening is low) and (grain size is high) and (acicularity is medium) and (dislocation density is high) and (decomposition product is high) then (Elastic Modulus is high)

13. If (volume fraction of $\beta$ is low) and (solution hardening is low) and (grain size is low) and (dislocation density is high) and (decomposition product is high) then (Elastic Modulus is medium)

14. If (volume fraction of $\beta$ is low) and (solution hardening is low) and (grain size is medium) and (dislocation density is medium) then (Elastic Modulus is high)

15. If (volume fraction of $\beta$ is low) and (solution hardening is high) and (grain size is medium) and (acicularity is medium) and (dislocation density is high) and (decomposition product is high) then (Elastic Modulus is low-medium)

In this case also it can be seen that the volume fraction of $\beta$ is directly correlated to the elastic modulus in the expected manner. All other microstructural features have highly complicated relation with the output. The model predictions, as shown in Fig. 12, are found to be good enough for all practical purposes.

The surface views for input/output relationships generated by the FIS from the elicited rules are shown in Fig. 13. It can be seen that the grain size, the solid solution hardening and dislocation density do not have any significant effects on the elastic modulus. The elastic modulus initially increases with increase in $\beta$ content, but decreases sharply with further increase. This indicates that the two phase structure has a higher elastic modulus. The elastic modulus is lowest with moderate precipitation hardening. As it can be seen in the case of yield strength also, the role of $\beta$ decomposition products are 'tricky' and may require further investigations. The increase in acicularity of the structure decreases the elastic modulus; this may indicate the formation of $\alpha^{\prime}$ and $\alpha^{\prime \prime}$.

\section{Alloy design}

To design an alloy for orthopaedic and dental applications the primary considerations are its mechanical properties and biocompatibility. In the case of mechanical properties, on the one hand the strength of the material should be high enough to bear the load, and on the other hand, the elastic modulus of the alloy has to be as close as possible to the stiffness of the bone to avoid the problem stress shielding. As these two objectives are conflicting in nature, multi- 
(C2015. This manuscript version is made available under the CC-BY-NC-ND 4.0 license http://creativecommons.org/licenses/by-nc-nd/4.0/

objective optimization may be a solution for effective design. In this case, evolutionary algorithm based RSSA is used to locate the Pareto solutions for designing the alloys. As in the case of multi-objective optimization a unique optimum solution may not be found, instead of the several non-dominated solutions, which are individually better in at least one objective compared to other such solutions, for the Pareto front may be the compromise solution. The developed rule-based models are now used as the evaluation function of the two mechanical properties (viz. yield strength and elastic modulus). As the alloy will be used for the aged section of the masses, alloy costs represent the third objective of the present problem. As the cost of the processing is same for all Ti alloys, the cost of the Ti and other alloying additions are only considered to create the objective function. A simple weighted summation method (amount of the alloying element multiplied by its cost) is employed. The costs of the alloying elements are mostly collected from ref. [55] and are converted to GBP/Kg. The objective function thus generated can be described as follows:

Cost $=1.5^{*} \mathrm{Al}+315^{*} \mathrm{~V}+21 * \mathrm{Zr}+24 * \mathrm{Mo}+98 * \mathrm{Nb}+270 * \mathrm{Ta}+0.5 * \mathrm{Fe}+15 * \mathrm{Sn}+8 * \mathrm{Cr}+$ $18 * \mathrm{Ti}$

$\left[\mathrm{Ti}=100-\sum(\right.$ all elements $\left.)\right]$

The biocompatibility issue was taken into account using two measures, viz. the coefficient of fibroblast outgrowth and the relative growth rate of L929 cells. The published values for the elements [41] are weighted according to the percentage added and summed, as in equations (6) and (7). The relation is constrained to a value $(\geq 100)$, which is described as safe for orthopaedic implants.

Coefficient of Fibroblast Outgrowth

$=0.8 * \mathrm{Al}+0 * \mathrm{~V}+1.18 * \mathrm{Zr}+1.18 * \mathrm{Nb}+1.17 * \mathrm{Ta}+0 * \mathrm{Mo}+1.15 * \mathrm{Cr}+0.55 * \mathrm{Fe}+1.3 * \mathrm{Sn}+$ $1.57 * \mathrm{Ti}$

Relative Growth rate of $L 929$ cell

$=1.2 * \mathrm{Al}+0 * \mathrm{~V}+1.1 * \mathrm{Zr}+1.0 * \mathrm{Nb}+0.9 * \mathrm{Ta}+1.12 * \mathrm{Mo}+0.94 * \mathrm{Cr}+0 * \mathrm{Fe}+1.3 * \mathrm{Sn}+$ $1.04 * \mathrm{Ti}$

The aluminium equivalent, suggested to be less than 9, for maintaining the toughness of the alloy at adequate level, the third constraint imposed. Ignoring the oxygen, nitrogen and carbon content, it is described by equation $(8)[8,11]$ :

Aluminium Equivalent $=\mathrm{Al}+\mathrm{Sn} / 3+\mathrm{Zr} / 6$

The multi-objective optimization using the above three objectives and three constraints is implemented using Multi-objective Reduced Space Searching Algorithm (MO-RSSA) [36]. 
(C2015. This manuscript version is made available under the CC-BY-NC-ND 4.0 license http://creativecommons.org/licenses/by-nc-nd/4.0/

In the MO-RSSA algorithm, several important parameters are used to control the optimization process, such as the decreasing parameter $C_{1}$, the increasing parameter $C_{2}$, the changing ratio $K$, the decreasing threshold $m$ and the frequency parameter $H$. The decreasing parameter $C_{1}$ and the increasing parameter $C_{2}$ are used to choose the right moment for shifting the search space. The scale of the search space variation is determined from the changing ratio $K$. The decreasing threshold $m$ controls the achievable minimum size of the search space. The frequency parameter $H$ relates to the frequency of the weight changing in the random weighted aggregation mechanism, which was designed to solve the problems with multiple objectives. In this work, the following parameters were used in MO-RSSA: $C_{1}=3$, $C_{2}=1, K=0.5, m=20$, and $H=1000$.

The Pareto front developed through the multi-objective optimization is shown in Fig. 14. The solutions have a significant variation in the strength and cost of the alloys, but the elastic modulus is within a narrow range. The detail analysis of the non-dominated solutions is reported elsewhere [26]. The solutions at the knee region of the Pareto front are considered for further studies, and based on which three alloys are designed for experimantal validation.

\section{Experimental validation}

Designed Ti alloys are developed from under vaccum melting furnace due to the high oxidation tendency of a few elements. The composition of the alloys are shown in the Table 2. Three developed as cast Ti alloys are homoginized at $900^{\circ} \mathrm{C}$ and furnace cooled. Then again alloys are solutionized at 950,700 and $850^{\circ} \mathrm{C}$ for alloys 1,2 and 3 respectively, with soaking time of lhour. The solutionizing of the alloys are done above their $\beta$ transus temperature, which are calculated from literature [56]. After homogenization, one set of samples are water quench, and the other set are air cooled. A portion of the alloys are hot rolled with a $20 \%$ deformation.

The strength and elastic modulus of the developed alloys are measured using standard microhardness techniques. The samples are subjected to micro-vickers for measuring the yield strength in Leco Micro hardness Tester LM 100. The yield strength of the samples are calculated from the following equation [57].

$\sigma_{y}=(332 \pm 18) \cdot H_{V}-(218 \pm 30)$ 
(C2015. This manuscript version is made available under the CC-BY-NC-ND 4.0 license http://creativecommons.org/licenses/by-nc-nd/4.0/

where $\sigma_{y}$ is the yield strength and $H_{V}$ is the Vickers hardness. The results are given in Table 3 along with the yield strength of commercial wrought Ti-6Al-4V measured in the same way. The processing conditions AC, WQ and HR denote air cooled, water quenched and hot rolled respectively. It is seen that in the case of Alloy 2, the strength level is lower than Ti-6Al-4V, the rest two alloys have superior strength level. It should also be noted here that the amount of $\beta$ stabilizers is maximum in Alloy 2. Hence, the presence of a higher amount of $\beta$ may have reduced the strength.

The eastic modulus of the alloys are measured through Knoop micro-hardness method. It is known that the Knoop hardness

$\mathrm{H}_{\mathrm{K}}=14.229 \frac{p}{(L)^{2}}$

where $P$ is the applied test load in $\mathrm{N}, L$ is the long indentation diagonal lengths in $\mathrm{m}$, and 14.229 is the geometrical constant of the diamond pyramid [58]. Again it is reported that $w$ is the width of the indentation then

$\frac{w}{L}=\frac{w^{\prime}}{L^{\prime}}-0.45 \frac{H_{K}}{E}$

where $W^{\prime} / L^{\prime}$ theoretical ratio of length and width and is equal to 0.1406 , calculated from the geometrical characteristics of the Knoop indenter. Thus, the equation becomes as follows :

$\frac{W}{L}=0.1406-0.45 \frac{H_{K}}{E}$

The elastic modulus $\mathrm{E}$ of the three different compositional Ti alloys, as measured through Knoop hardness method in the same hardness testing machine as above, and their respective processing conditions are shown in the Table 4. It can be seen that though the E values varied extensively with processing conditions but most of the results are encouraging and almost up to expectations. In all cases, the E values are consistently low in water quenched conditions. Alloy 2, which did not provide a good strength, has the lowest $\mathrm{E}$ at water quenched condition. But the other alloys also had comparable results. A special mention should be made about Alloy 3; in this alloy the chief alloying addition is $\mathrm{Cr}$ to make the alloy less expensive. Still it has provided a good combination of high strength and low modulus of elasticity.

A priliminary study of the microstructure of the alloys in water quenched conditions was carried out using light microscope (Fig. 15). The alloys was etched using Kroll's reagent, which is mostly suitable for Ti alloys [59]. The micrographs shows that in the case of alloys 1 and 3 the second phase (presumably $\alpha$ ) is present within the $\beta$ matrix significantly, where as 
(C2015. This manuscript version is made available under the CC-BY-NC-ND 4.0 license http://creativecommons.org/licenses/by-nc-nd/4.0/

in case of Alloy 2 the amount of second phase is significantly low. This explains the low strength and elastic modulus of Alloy 2. The microstructure of the three alloys is significantly different from each other, and thus requires in depth characterization. It is worth here that the reason for the variations of the elastic modulus due to different processing need to be explored. The presence of other phases, such as $\alpha^{\prime}, \alpha^{\prime \prime}$ and $\omega$, is known to have a strong influence on the modulus $[11,15,60]$. Thus, the analysis of the microstructural constituents may provide clues as to the behavior of the alloys at different processing conditions.

\section{Conclusions}

1. Prior knowledge in imprecise linguistic form could be successfully utilised for developing predictive models for the mechanical properties of Ti alloys using fuzzy logic.

2. Prior experimental finding may be used simultaneously to refine and develop a semiempirical two-layered fuzzy inference system, incorporating the microstructural features.

3. The fuzzy models for strength and elastic modulus may be used as objective functions for the multi-objective optimization method using RSSA.

4. The Pareto solutions provide sufficient information for designing alloys. The solutions for the knee region of the Pareto front are used for decision making.

5. The experimental validation of the designed alloy provide encouraging results in terms of strength and elastic modulus of the alloys. Further in depth chracterization of the alloy is sure to establish a few novel alloy systems superior in properties than the existing ones.

\section{Acknowledgement}

Prof. S. Datta and Prof. M. Mahfouf are grateful to Royal Academy of Engineering, UK for their support to the present investigation in the Research Exchange scheme. N. Sultana is grateful to Council of Scientific and Industrial Research, India. All authors wish to thank all reviewers for their comments which helped to improve the quality of this paper.

\section{References:}

1. Mitsuo Niinomi. Fatigue performance and cyto-toxicity of low rigidity titanium alloy Ti-29Nb-13Ta-4.6Zr. Biomaterials 2003; 24: 2673-2683. 
@2015. This manuscript version is made available under the CC-BY-NC-ND 4.0 license http://creativecommons.org/licenses/by-nc-nd/4.0/

2. Titanium Alloy Guide. RMI Titanium company An RTI internationals Metals, Inc Company.

3. Mohsin Talib Mohammed, Zahid A. Khan, Arshad N. Siddiquee. Beta Titanium Alloys: The Lowest Elastic Modulus for Biomedical Applications: A Review World Academy of Science, Engineering and Technology. International Journal of Chemical, Nuclear, Materials and Metallurgical Engineering 2014; Vol.8: No.8.

4. H. S. Kim, T. Y. Ra, I. D. Yeo, H. J. Bang, Y. G. Yoo, W. Y. Kim. Microstructure, Elastic Modulus and Tensile Properties of Ti-Nb-O Alloy System J. Mater. Sci. Technology 2008; Vol. 24:No.1.

5. Han-Cheol CHOE, Viswanathan S. SAJI, Yeong-Mu KO. Mechanical properties and corrosion resistance of low rigidity quaternary titanium alloy for biomedical applications, Trans. Nonferrous Met. Soc. China 2009; 19:862-865

6. Hin, T.S. (Ed.) Engineering Materials for Biomedical Applications. Biomaterials Engineering and Processing. World Scientific Publishing Co. Pte. Ltd.: Singapore, 2004.

7. Carlos Oldani, Alejandro Dominguez (2012). Titanium as a Biomaterial for Implants, Recent Advances in Arthroplasty. Dr. Samo Fokter (Ed.), ISBN: 978-953-307-990-5. http://www.intechopen.com/books/recent-advances-in-arthroplasty/titanium-as-abiomaterial-for-implants

8. Vydehi Arun Joshi. Titanium Alloys, An Atlas of Structures and Fracture Features, Taylor \& Francis.

9. E. Eisenbarth, D. Velten, M. Muller, R. Thull, J. Breme. Biocompatibility of $\beta$ stabilizing elements of titanium alloys Biomaterials 2004; 25: 5705-5713

10. Polmear, I.J. "Light Alloys" From Traditional Alloys to Nanocrystals, 4th Ed.; Butterworth-Heinemann: London, UK, 2006. P 299-365.

11. I. Weiss, S. L. Semiatin. Thermomechanical processing of beta titanium alloys - an overview. Materials Science and Engineering 1998; A243 : 46-65

12. Yuhua Li, Chao Yang, Haidong Zhao, Shengguan Qu, Xiaoqiang Li, Yuanyuan Li. Review New Developments of Ti-Based Alloys for Biomedical Applications. Materials 2014; 7: 1709-1800. 
(C2015. This manuscript version is made available under the CC-BY-NC-ND 4.0 license http://creativecommons.org/licenses/by-nc-nd/4.0/

13. Ban Jae-Sam, Lee Kyung-Won, Kim Sun-Jin, Cho Kyu-Zong. A study on the microstructural property and thermal property of Ti-alloys without $\mathrm{Al}$ as biomaterials. Journal of Mechanical Science and Technology 2008; 22: 1447-1450.

14. Marjan Bahrami Nasab, Mohd Roshdi Hassan. Metallic Biomaterials of Knee and Hip. A ReviewTrends Biomater. Artif. Organs 2010; Vol. M 24(1): pp 69-82.

15. Tomomichi Ozaki, Hiroaki Matsumoto, Sadao Watanabe, Shuji Hanada. Beta Ti Alloys with Low Young's Modulus. Materials Transactions 2004; Vol. 45, No. 8 pp. $2776-2779$.

16. Mukta Kulkarni, Anca Mazare, Patrik Schmuki, Aleš Iglič. Biomaterial surface modification of titanium and titanium alloys for medical applications. Nanomedicine. Chapter 5:111-133.

17. M. Gonza' lez, J. Pen a, J.M. Manero, M. Arciniegas, F.J. Gil. Design and Characterization of New Ti-Nb-Hf Alloys. JMEPEG (2009) 18:490-495

18. Mohamed Abdel-Hady Gepreel, Mitsuo Niinomi. Opinion Piece Biocompatibility of Ti-alloys for long-term implantation. Accepted in Journal of the Mechanical behavior of biomedicals materials. http://dx.doi.org/10.1016/j.jmbbm.2012.11.014

19. M. Mahfouf, M Gama, G. Panoutsos. Right First-Time' production of materials: A reality or a myth? Materials and Manufacturing Processes 2009; 24(1): pp.78-82.

20. Q. Zhang, M. Mahfouf, J. R. Yates, C. Pinna, G. Panoutsos, S. Boumaiza, R. J. Greene, L. de Leon. Modeling and Optimal Design of Machining-induced Residual Stresses in Aluminium Alloys Using a Fast Hierarchical Multiobjective Optimization Algorithm. Materials and Manufacturing Processes 2011; 26 (3): pp. 508-520.

21. D. Raabe, B. Sander, M. Friák, D. Ma, J. Neugebauer. Theory-guided bottom-up design of $\beta$-titanium alloys as biomaterials based on first principles calculations: Theory and experiments. Acta Materialia 2007; 55: 4475-4487.

22. Abdulrafiu Tunde Raji, Sandro Scandolo, Riccardo Mazzarello, Schadrack Nsengiyumva, Margit Härting, David Thomas Britton. Ab initio pseudopotential study of vacancies and self-interstitials in hcp titanium. Philosophical Magazine 2009; 89: $1629-1645$.

23. W.A. Counts, M. Friák, D. Raabe, J. Neugebauer. Using ab initio calculations in designing bec Mg-Li alloys for ultra-lightweight applications. Acta Materialia 2009; 57: 69-76. 
C2015. This manuscript version is made available under the CC-BY-NC-ND 4.0 license http://creativecommons.org/licenses/by-nc-nd/4.0/

24. H. Katayama-Yoshida, K. Sato. Materials design for semiconductor spintronics by ab initio electronic-structure calculation. Physica B: Condensed Matter 2003; 327: $337-$ 343.

25. Jorge Íñiguez, L. Bellaiche. Ab Initio Design of Perovskite Alloys with Predetermined Properties: The Case of $\mathrm{Pb}\left(\mathrm{Sc}_{0.5} \mathrm{Nb}_{0.5}\right) \mathrm{O}_{3}$. Phys. Rev. Lett. 2001; 87, 095503-6.

26. Shubhabrata Datta, Qian Zhang, Nashrin Sultana, Mahdi Mahfouf. Optimal Design of Titanium Alloys for Prosthetic Applications Using a Multiobjective Evolutionary Algorithm. Materials and Manufacturing Processes 2013; 28: 741-745.

27. N. Sultana, S. Sikdar (Dey), P. P. Chattopadhyay, S. Datta. Informatics based design of prosthetic Ti alloys. Materials Technology. Advanced Biomaterials 2014; 29:B1B69.

28. S. Datta, P. P. Chattopadhyay. Soft computing techniques in advancement of structural metals. Int. Mater. Rev. 2013; 58: 475-504.

29. S. Dey, S. Datta, P.P. Chattopadhyay, J. Sil. Modeling the Properties of TRIP Steel using AFIS: a Distributed Approach. Computational Materials Science. 2008; 43: $501-511$.

30. A.K. Nandi, K. Deb, S. Ganguly, S. Datta. Investigating the role of metallic fillers in particulate reinforced flexible mould material composites using evolutionary algorithms. Applied Soft Computing 2012; 12: 28-39.

31. K. Rajan. Materials Informatics. Mater. Today 2005; 38-45.

32. H. K. D. H. Bhadeshia. Mathematical models in materials science. Mater. Sci. Technol. 2008; 24: 128-136.

33. L.A. Zadeh. Outline of a new approach to the analysis of complex systems and decision processes, IEEE Transactions of Systems, Man, and Cybernetics 1973; SMC-3(1), 24-44.

34. Mamdani, E.H. Assilian, S. An experiment in linguistic synthesis with a fuzzy logic controller. International Journal of Man-Machine Studies 1975; 7:1-13.

35. Zhang, Q., Mahfouf, M. A new Reduced Space Searching Algorithm (RSSA) and its application in optimal design of alloy steels. Proc. 2007 IEEE Cong. Evolutionary Computation, Singapore 2007; pp. 1815-1822. 
C2015. This manuscript version is made available under the CC-BY-NC-ND 4.0 license http://creativecommons.org/licenses/by-nc-nd/4.0/

36. Zhang, Q.; Mahfouf, M. A nature-inspired multi-objective optimization strategy based on a new reduced space searching algorithm for the design of alloy steels. Engineering Applications of Artificial Intelligence 2010; 23:660-675.

37. K. Deb. Optimization for Engineering Design: Algorithms and Examples. Prentice-Hall of India Pvt. Limited. New Delhi 1995.

38. D.E. Goldberg. Genetic Algorithms in Search, Optimization and Machine Learning. Pearson-Education New Delhi 2002.

39. N. Chakraborti. Genetic algorithms in materials design and processing. International Materials Reviews 2004; Vol. 49 No. 3-4:246-260.

40. K. Deb. Multiobjective Optimization Using Evolutionary Algorithms. John Wiley \& Sons Ltd. Chichester 2001.

41. D. Kuroda, M. Niinomi, M. Morinaga, Y. Kato and T. Yashiro: Design and mechanical properties of new $\beta$ type titanium alloys. Mater. Sci. Eng. A, 1998; A243, 244-249.

42. J. A. Davidson and P. Kovacs. Biocompatable, low modulus, titanium alloys for medical implants. 1992; US Patent 5,169,597.

43. http://www.feppd.org/ICB-

Dent/campus/biomechanics_in_dentistry/ldv_data/mech/basic_bone.htm

44. S. G. Schneidera, H. M. da Silva and C. de Moura Neto. Study of the non-linear stress-strain behavior in Ti-Nb-Zr Alloys. Mater. Res. 2005; Vol.8, No.4:435-438.

45. M. Niinomi. Recent research and development in titanium alloys for biomedical applications and healthcare goods. Sci. Technol. Adv. Mater., 2003; 4: 445-454.

46. K. K. Wang, L. J. Gustavson and J. H. Dumbleton. High strength low modulus, ductile biocompatible Ti alloys. US Patent 4,857,269, 1989.

47. http://www.efunda.com/materials/alloys/titanium/properties.cfm

48. M. J. Donachie, Jr: 'Titanium: a technical guide', 2nd edn. 2000, Materials Park, OH, ASM International.

49. S. G. Schneider, C. A. Nunes, S. O. Rogero, O. Z. Higa and J. C. Bressiani. Mechanical properties and cytotoxic evaluation of the $\mathrm{Ti}-3 \mathrm{Nb}-13 \mathrm{Zr}$ alloy. Biomeca'nica 2000; 8, (1):84-87.

50. G. He, M. Hagiwara. Ti alloy design strategy for biomedical applications. Materials Science and Engineering 2006; C 26:14 - 19. 
C2015. This manuscript version is made available under the CC-BY-NC-ND 4.0 license http://creativecommons.org/licenses/by-nc-nd/4.0/

51. H. Ishibuchi, T. Yamamoto, T. Nakashima, Fuzzy data mining: effect of fuzzy discretization: Proceedings of the First IEEE International Conference on Data Mining, 2001, pp. 241-248.

52. W.F. Cui, A.H. Guo 'Microstructures and properties of biomedical TiNbZrFe $\beta$ titanium alloy under aging conditions' Materials Science and Engineering 2009; A $527: 258-262$.

53. Cheng - Lin Li, Li Na Zou, Yan-Yan Fu, Wen-Jun Ye, Song-Xiao Hui Effect of heat-treatments on microstructure and property of a high strength/ toughness $\mathrm{Ti}-8 \mathrm{~V}-$ 1.5Mo-2Fe-3Al alloy. Materials Science \& Engineering 2014; A 616:207-213.

54. R. Filip, K. Kubiak, W. Ziaja, J. Sieniawski Journal of Materials Processing Technology 2003; $133: 84-89$.

55. http://www.metalfirst.com

56. Z. Guo, S. Malinov, W. Sha. Modelling beta transus temperature of titanium alloys using artificial neural network. Computational Materials Science 2005; 32:1-12.

57. Osamu Takakuwa, Yusuke Kawaragi, Hitoshi Soyama. Estimation of the Yield Stress of Stainless Steel from the Vickers Hardness Taking Account of the Residual Stress Journal of Surface Engineered Materials and Advanced Technology, 2013; 3 : 262268.

58. H.S. Güdera, E. Sahina, O. Sahina, H. Göçmezb, C. Duranc and H. Ali Çetinkara. Vickers and Knoop Indentation Microhardness Study of $\beta$-SiAlON Ceramic. Acta Physica Polonica 2011; A; No.6 Vol. 120.

59. M.T. Jovanovic', S. Tadic', S. Zec, Z. Mis`kovic', I. Bobic. The effect of annealing temperatures and cooling rates on microstructure and mechanical properties of investment cast Ti-6Al-4V alloy. Materials and Design 2006; 27:192-199.

60. Yen-Huei Hon, Jian-Yih Wang and Yung-Ning Pan. Composition/Phase Structure and Properties of Titanium-Niobium Alloys. Materials Transactions; 2003 Vol. 44, No. 11 pp. $2384-2390$. 
C2015. This manuscript version is made available under the CC-BY-NC-ND 4.0 license http://creativecommons.org/licenses/by-nc-nd/4.0/

Table 1: List of input and output variables with their lower and upper limits

\begin{tabular}{|l|l|l|l|}
\hline S.No. & Variables & Lower Limit & Upper Limit \\
\hline 1 & Aluminium(Al) & 0 & 8 \\
\hline 2 & Vanadium $(\mathrm{V})$ & 0 & 15 \\
\hline 3 & Zirconium $(\mathrm{Zr})$ & 0 & 18 \\
\hline 4 & Molybdenum $(\mathrm{Mo})$ & 0 & 15 \\
\hline 5 & Niobium $(\mathrm{Nb})$ & 0 & 41.1 \\
\hline 6 & Tantalum $(\mathrm{Ta})$ & 0 & 30 \\
\hline 7 & Iron $(\mathrm{Fe})$ & 0 & 2.5 \\
\hline 8 & Tin $(\mathrm{Sn})$ & 0 & 15 \\
\hline 9 & Silicon $(\mathrm{Si})$ & 0 & 0.5 \\
\hline 10 & Chromium $(\mathrm{Cr})$ & 0 & 20 \\
\hline 11 & Testing Temperature & 25 & 850 \\
\hline 12 & Solutionising Temperature $\left(\mathrm{T}_{\text {soln }}\right)$ & 718 & 1000 \\
\hline 13 & Ageing Temperature $\left(\mathrm{T}_{\text {age }}\right)$ & 25 & 600 \\
\hline 14 & Ageing Time $\left(\mathrm{t}_{\text {age }}\right)$ & 0 & 4320 \\
\hline 15 & Cooling rate & 0.5 & 100 \\
\hline 1 & Elastic Modulus(EM) & 46 & 125 \\
\hline 2 & Yield Strength(YS) & 250 & 1317 \\
\hline & & & \\
\hline
\end{tabular}

Table 2: Developed alloys from soft computing technique

\begin{tabular}{|l|l|l|l|l|l|l|l|}
\hline Alloy & $\mathrm{Al}$ & $\mathrm{Zr}$ & $\mathrm{Mo}$ & $\mathrm{Nb}$ & $\mathrm{Ta}$ & $\mathrm{Sn}$ & $\mathrm{Cr}$ \\
\hline 1 & 6.9 & 4.1 & 7.0 & 0 & 0 & 9.9 & 10.1 \\
\hline 2 & 2.1 & 3.9 & 10.1 & 4.9 & 5.1 & 8.0 & 5.8 \\
\hline 3 & 2.0 & 0 & 0 & 0 & 0 & 12.8 & 18.2 \\
\hline
\end{tabular}


C2015. This manuscript version is made available under the CC-BY-NC-ND 4.0 license http://creativecommons.org/licenses/by-nc-nd/4.0/

Table 3: Yield strength calculated from Vickers hardness

\begin{tabular}{|l|l|l|l|l|l|}
\hline Alloy & Processing & Load (gf) & Dwell time (s) & $\mathrm{H}_{\mathrm{V}}(\mathrm{GPa})$ & YS (GPa) \\
\hline \multirow{4}{*}{2} & AC & 100 & 15 & 3.89 & 1.113 \\
\cline { 2 - 6 } & WQ & 100 & 15 & 3.8 & 1.082 \\
\cline { 2 - 6 } & HR & 100 & 15 & 3.753 & 1.065 \\
\hline \multirow{3}{*}{3} & AC & 100 & 15 & 2.90 & 0.767 \\
\cline { 2 - 6 } & WQ & 100 & 15 & 2.77 & 0.722 \\
\cline { 2 - 6 } & HR & 100 & 15 & 2.902 & 0.767 \\
\cline { 2 - 7 } & AC & 100 & 15 & 3.58 & 1.005 \\
\cline { 2 - 6 } & WQ & 100 & 15 & 3.78 & 1.075 \\
\cline { 2 - 6 } & HR & 100 & 15 & 3.69 & 1.044 \\
\hline Ti-6Al-4V & Wrought & 100 & 15 & 3.1451 & 0.851 \\
\hline
\end{tabular}

Table 4: Elastic modulus of the alloys

\begin{tabular}{|l|l|l|l|l|l|}
\hline Alloy & Processing & Load (gf) & Dwell time (s) & $\mathrm{H}_{\mathrm{K}}(\mathrm{GPa})$ & E (GPa) \\
\hline \multirow{4}{*}{1} & AC & 50 & 15 & 4.47 & 72.8 \\
\cline { 2 - 6 } & WQ & 50 & 15 & 4.6239 & 46.2 \\
\cline { 2 - 6 } & HR & 50 & 15 & 4.98 & 51.5 \\
\hline \multirow{3}{*}{3} & AC & 50 & 15 & 3.3924 & 100.9 \\
\cline { 2 - 6 } & WQ & 50 & 15 & 3.832 & 41.7 \\
\cline { 2 - 6 } & HR & 50 & 15 & 3.558 & 80.0 \\
\hline \multirow{3}{*}{3} & AC & 50 & 15 & 4.559 & 45.1 \\
\cline { 2 - 6 } & WQ & 50 & 15 & 4.691 & 52.2 \\
\cline { 2 - 6 } & HR & 50 & 15 & 4.64 & 72.8 \\
\hline Ti-6Al-4V & Wrought & 50 & 15 & 3.86 & 88.4 \\
\hline
\end{tabular}


C2015. This manuscript version is made available under the CC-BY-NC-ND 4.0 license http://creativecommons.org/licenses/by-nc-nd/4.0/

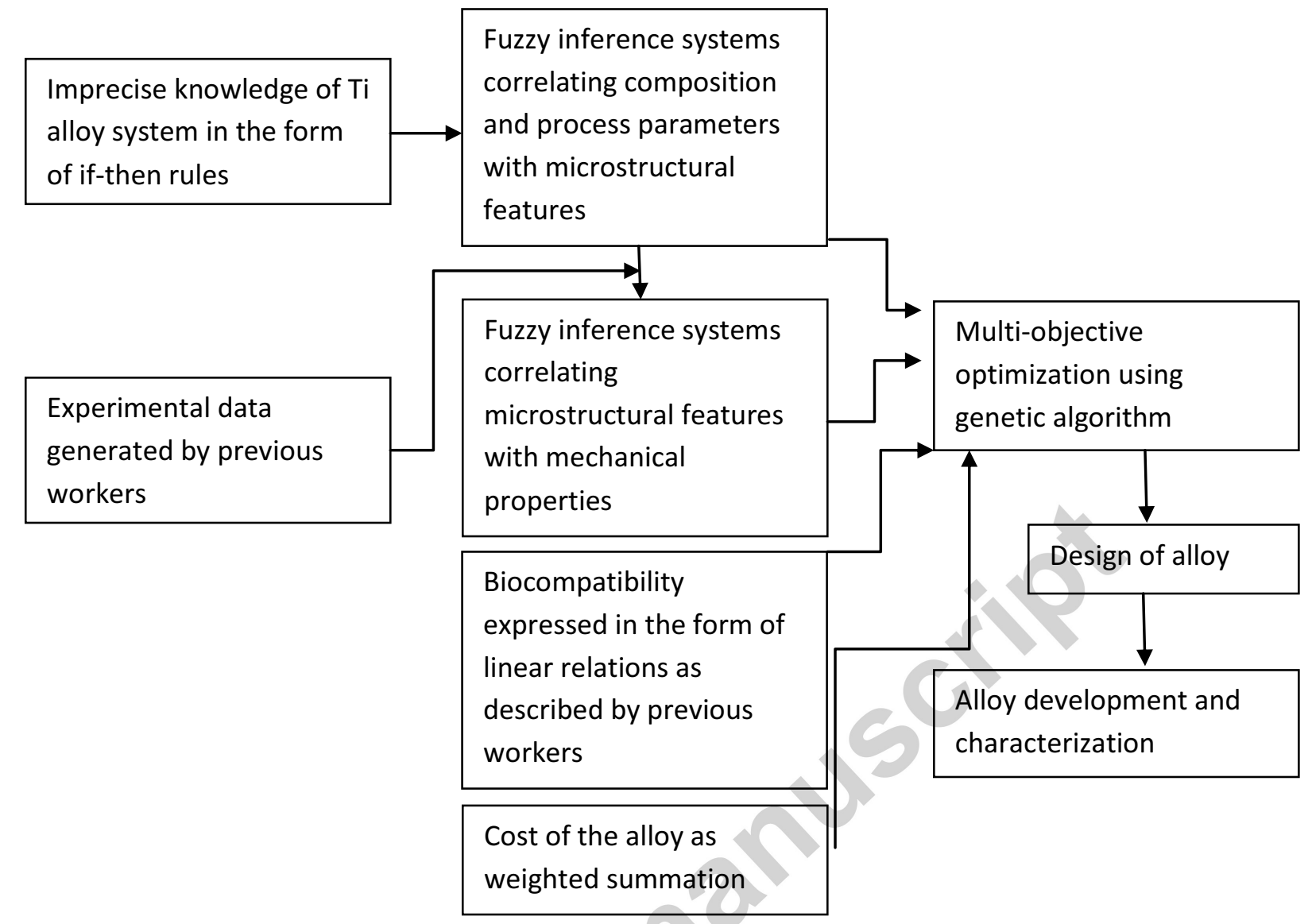


(C2015. This manuscript version is made available under the CC-BY-NC-ND 4.0 license http://creativecommons.org/licenses/by-nc-nd/4.0/

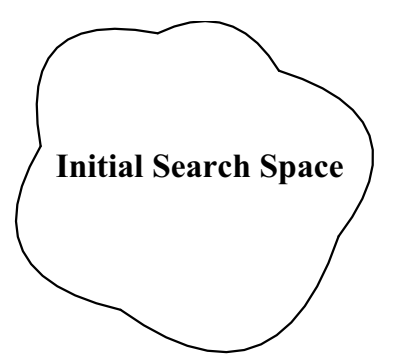

Step 1

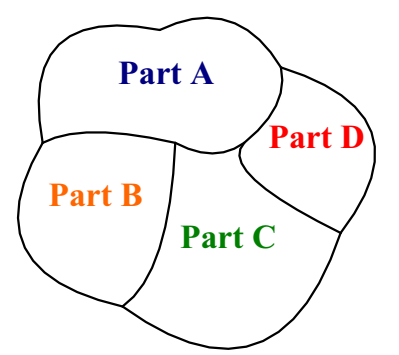

Divide the Initial Search

Space into Arbitrary Parts

Rank these Parts according to

the probability of the

candidates satisfying the

Step 2

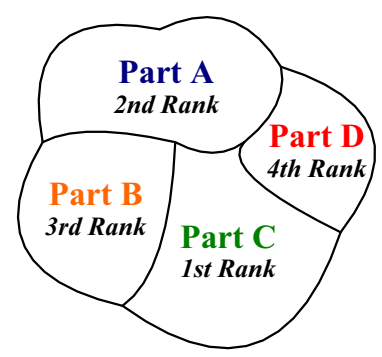

objective(s)

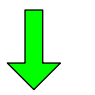

Search with the $1^{\text {st }}$

highest density within

Search with the $2^{\text {nd }}$

highest density within

\section{(}

Step 3
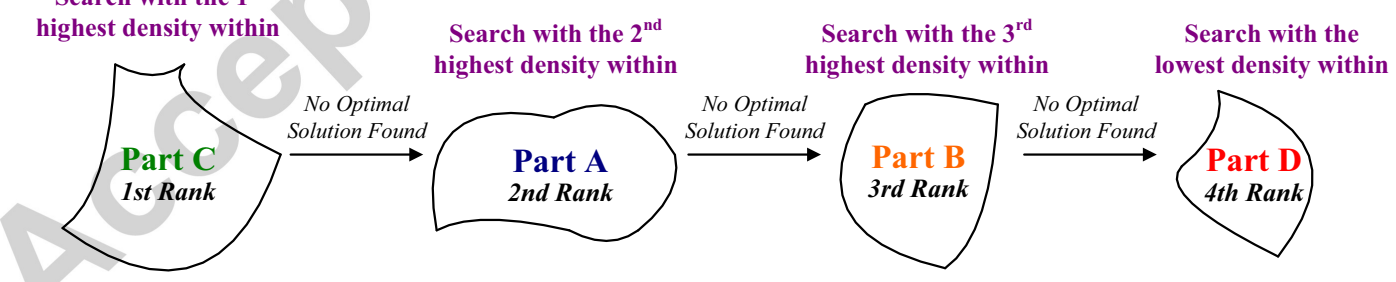

Fig. 1: The Reduced Space Searching strategy for optimisation 
C2015. This manuscript version is made available under the CC-BY-NC-ND 4.0 license http://creativecommons.org/licenses/by-nc-nd/4.0/

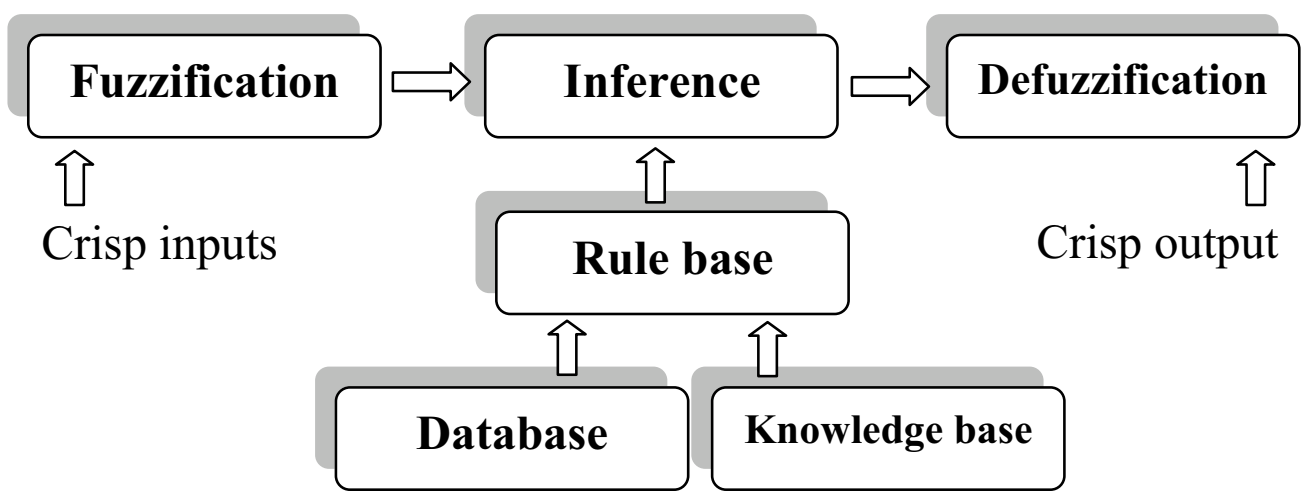

Fig. 2: Schematic of Mamdani Fuzzy Inference System

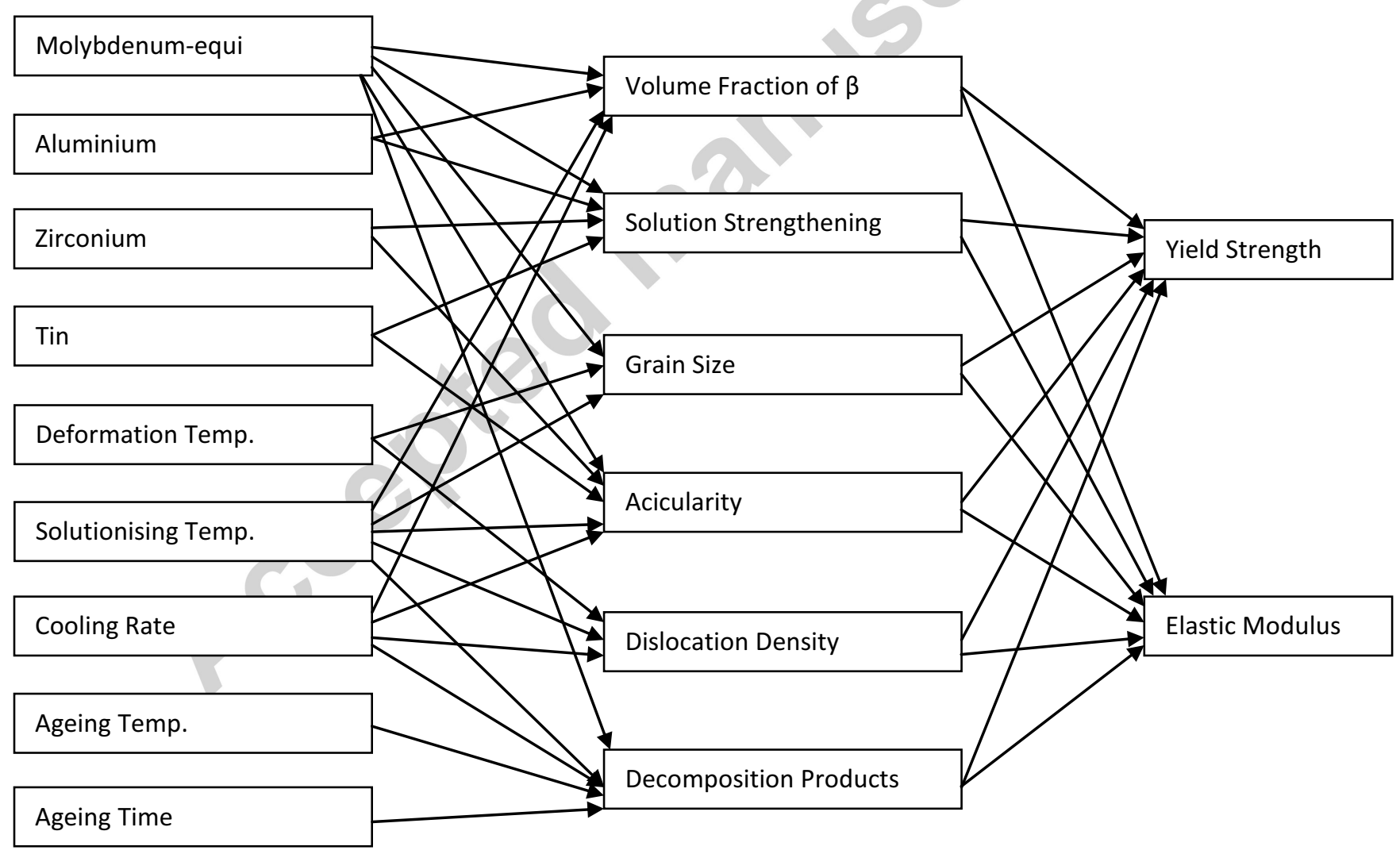

Fig. 3: Schematic of the fuzzy models (composition-process-microstructure-property correlation) 
(C2015. This manuscript version is made available under the CC-BY-NC-ND 4.0 license http://creativecommons.org/licenses/by-nc-nd/4.0/

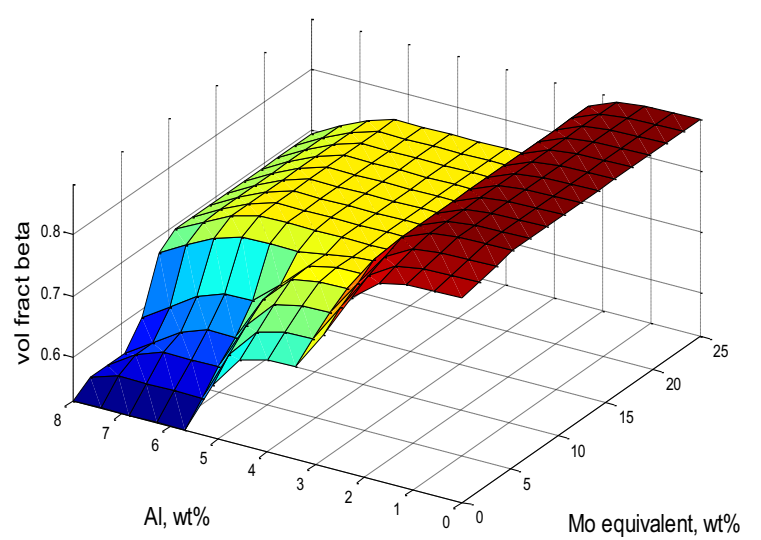

(a)

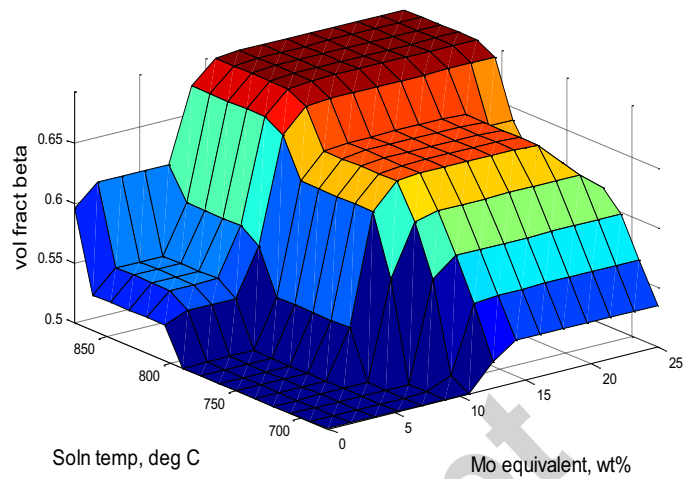

(b)

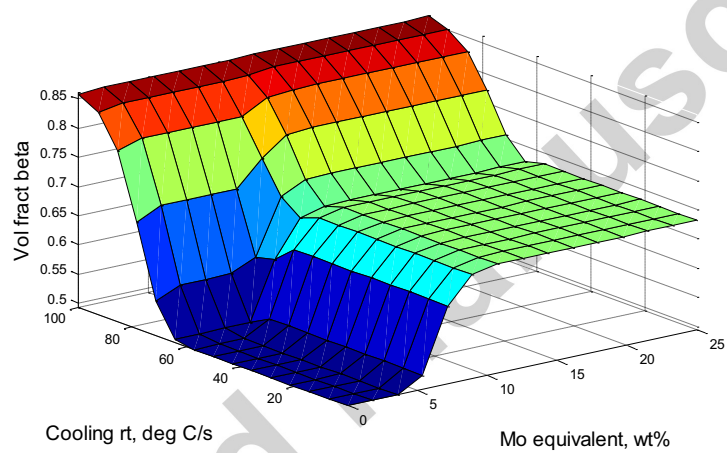

(c)

Fig. 4: Surface views generated by the FIS describing the effects of (a) Al and Mo equivalent, (b) Solutionising temperature and Mo equivalent and (c) Cooling rate and Mo equivalent on volume fraction of $\beta$. 
(C2015. This manuscript version is made available under the CC-BY-NC-ND 4.0 license http://creativecommons.org/licenses/by-nc-nd/4.0/

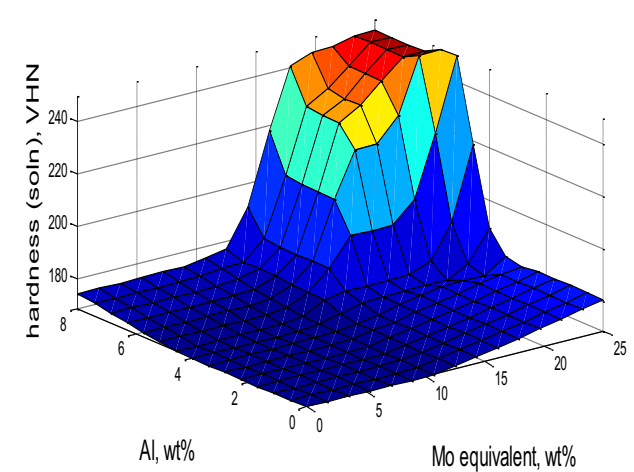

(a)

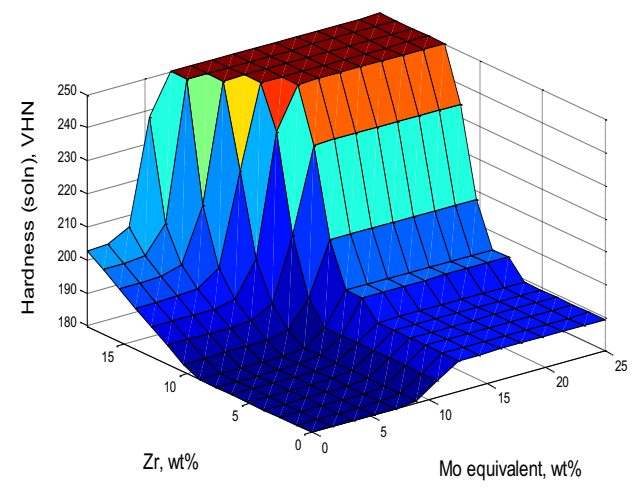

(b)

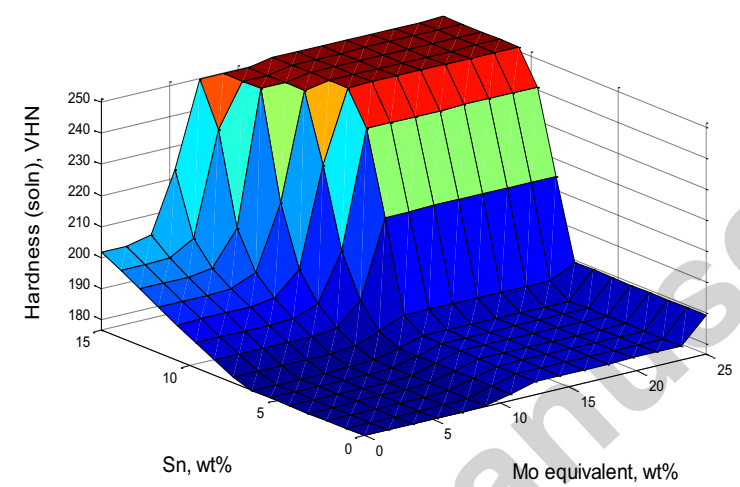

(c)

Fig. 5: Surface views generated by the FIS describing the effects of (a) Al and Mo equivalent, (b) $\mathrm{Zr}$ and Mo equivalent and (c) Sn and Mo equivalent on solid solution hardening.

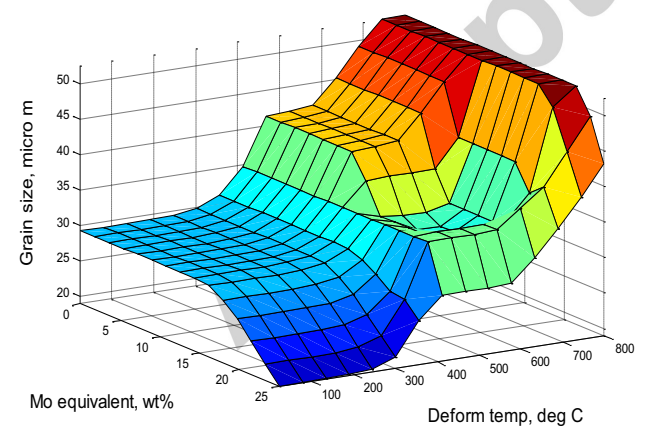

(a)

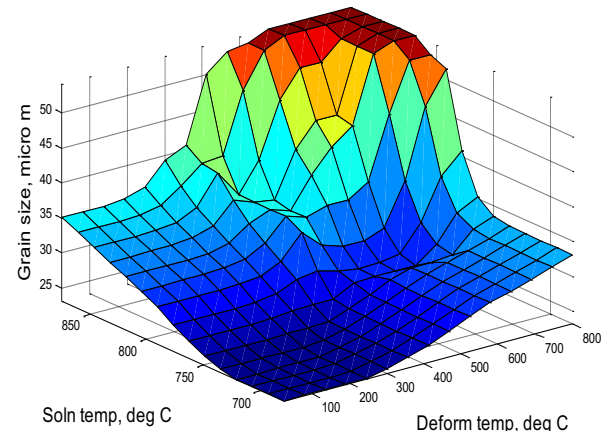

(b)

Fig. 6: Surface views generated by the FIS describing the effects of (a) Mo equivalent and deformation temperature, and (b) solutionising temperature and deformation temperature on grain size. 


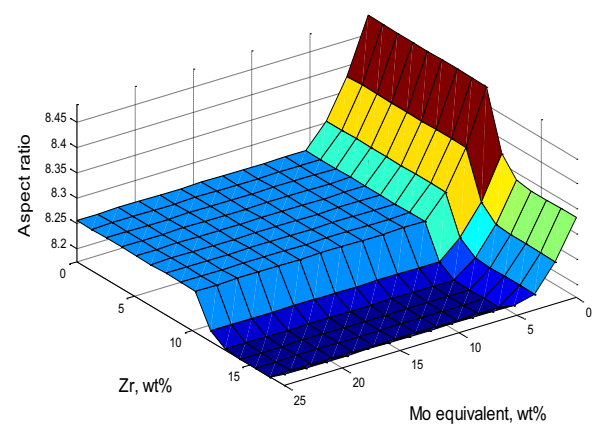

(a)
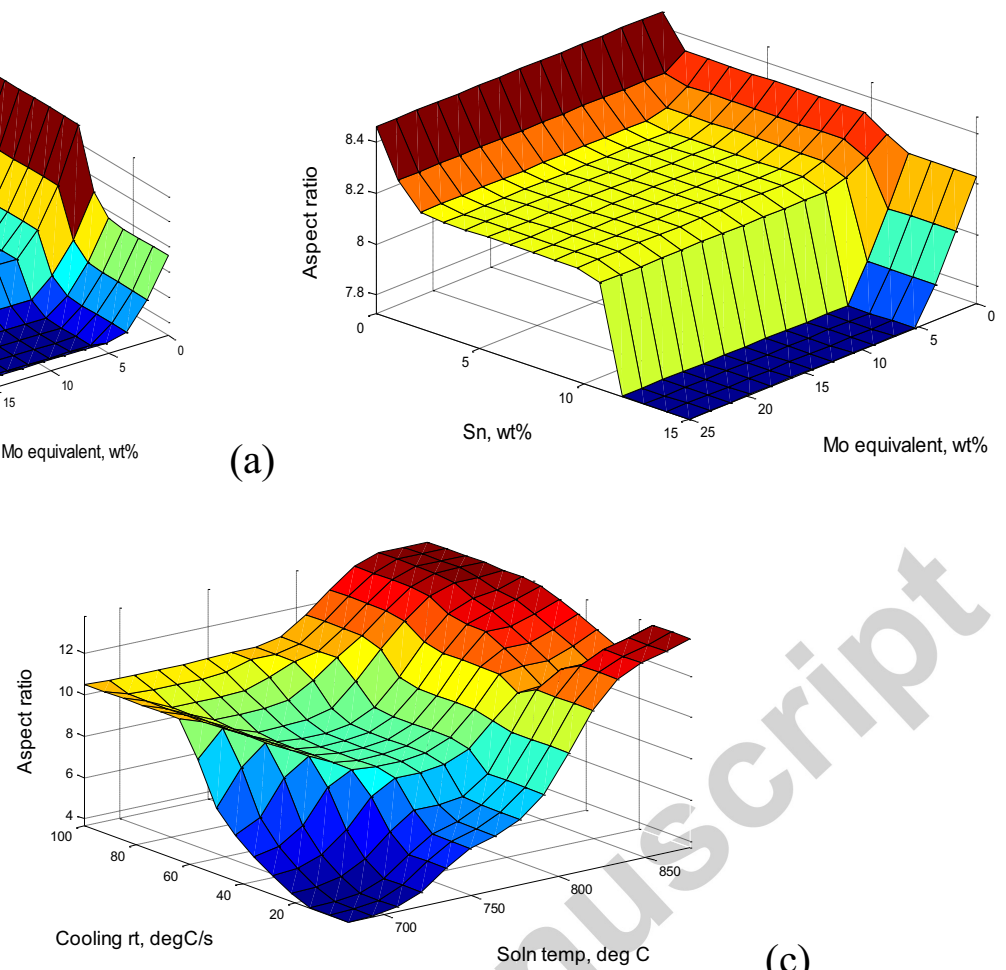

(b)

Soln temp, deg C

(c)

Fig. 7: Surface views generated by the FIS describing the effects of (a) Zr and Mo equivalent, (b) Sn and Mo equivalent, and (c) cooling rate and solutionising temperature on the acicularity of microstructure.
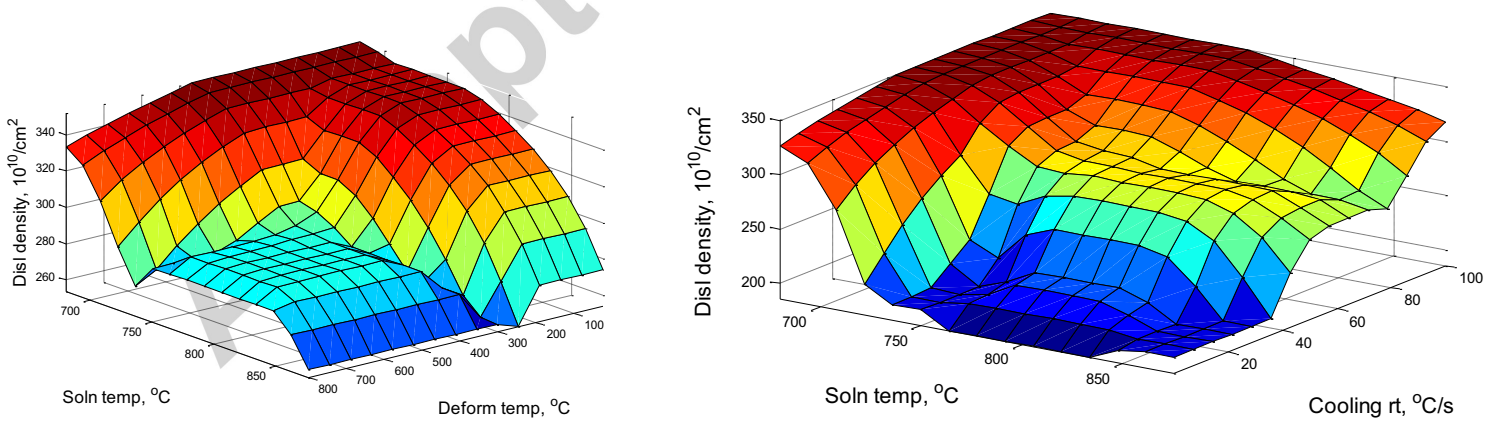

Fig. 8: Surface views generated by the FIS describing the effects of (a) solutionising and deformation temperatures, and (b) solutionising temperature and cooling rate on the dislocation density in the microstructure. 
C2015. This manuscript version is made available under the CC-BY-NC-ND 4.0 license http://creativecommons.org/licenses/by-nc-nd/4.0/

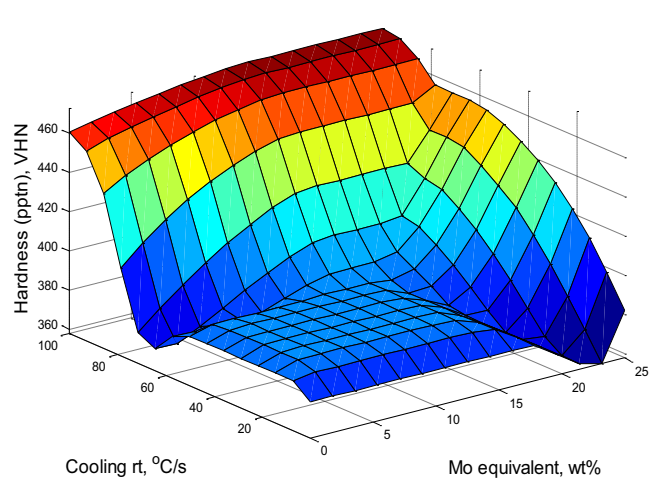

Cooling rt, ${ }^{\circ} \mathrm{C} / \mathrm{s}$

Mo equivalent, wt\%

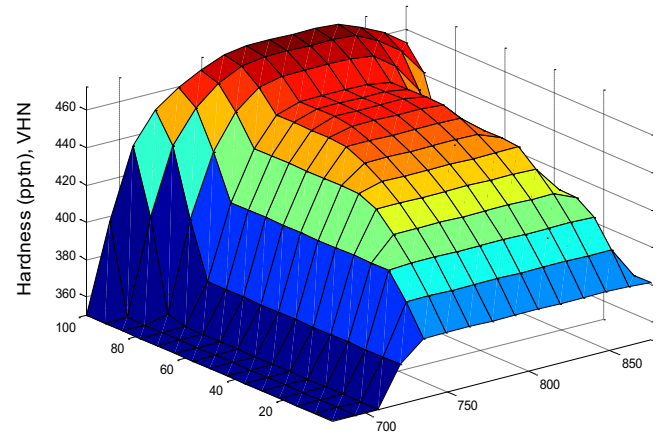

(a)

Soln temp, ${ }^{\circ} \mathrm{C}$

(b)

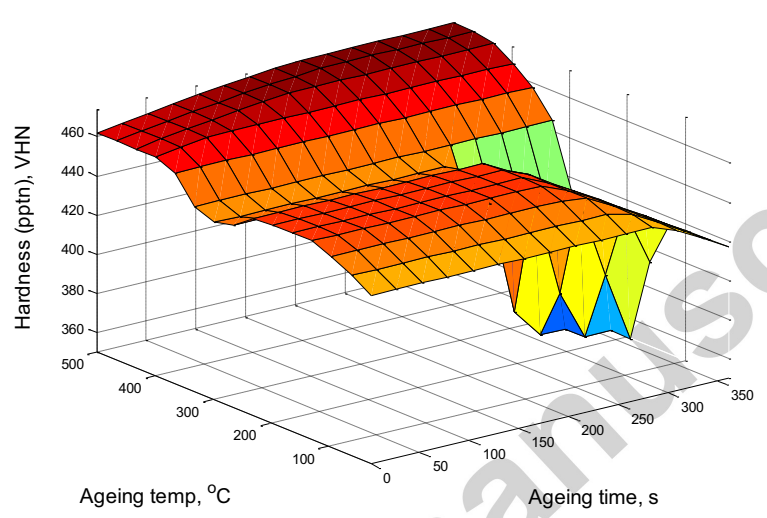

(c)

Fig. 9: Surface views generated by the FIS describing the effects of (a) cooling rate and Mo equivalent, (b) cooling rate and solutionising temperature, and (c) ageing temperature and ageing time on precipitation hardening.

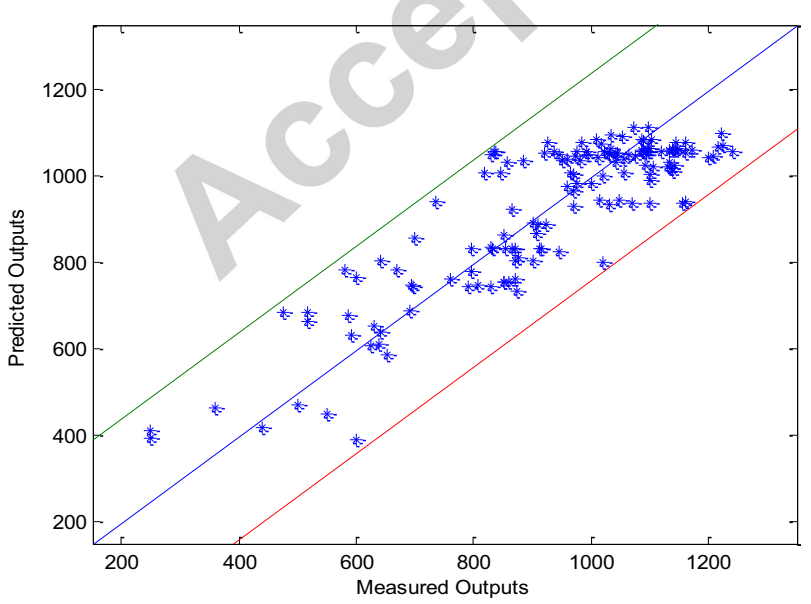

Fig. 10: Scatter plot showing model predicted versus measured yield strength values. 
C2015. This manuscript version is made available under the CC-BY-NC-ND 4.0 license http://creativecommons.org/licenses/by-nc-nd/4.0/

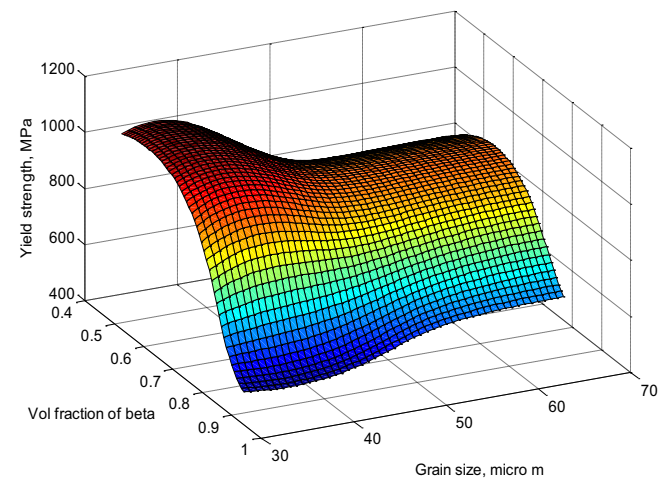

(a)

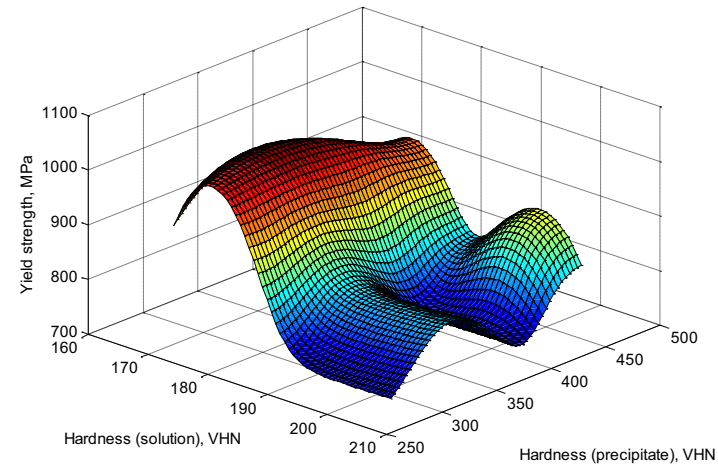

(b)

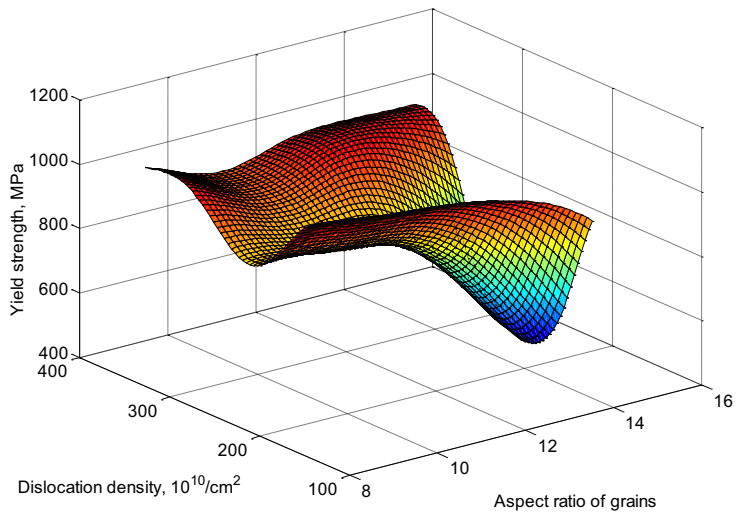

(c)

Fig. 11: Surface views generated by the FIS describing the effects of (a) volume fraction of $\beta$ and grain size, (b) solution and precipitation hardening, and (c) dislocation density and aspect ratio of grains on yield strength.

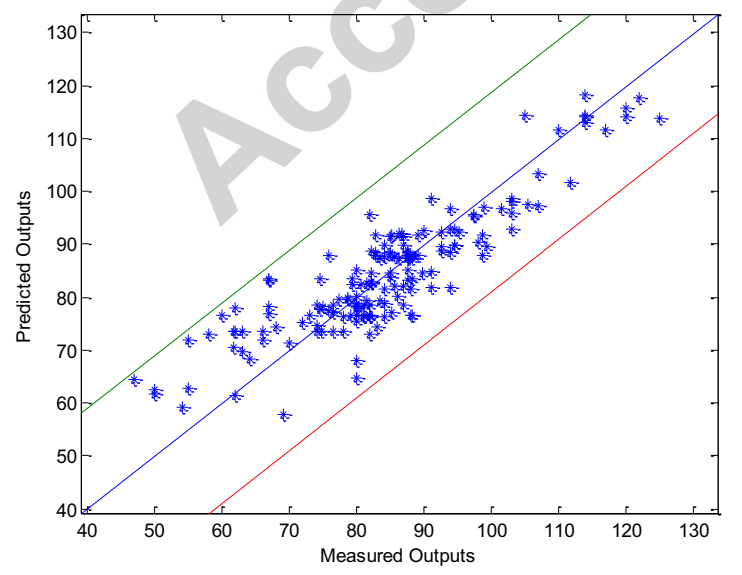

Fig. 12: Scatter plot showing model predicted versus measured elastic modulus values. 
C2015. This manuscript version is made available under the CC-BY-NC-ND 4.0 license http://creativecommons.org/licenses/by-nc-nd/4.0/
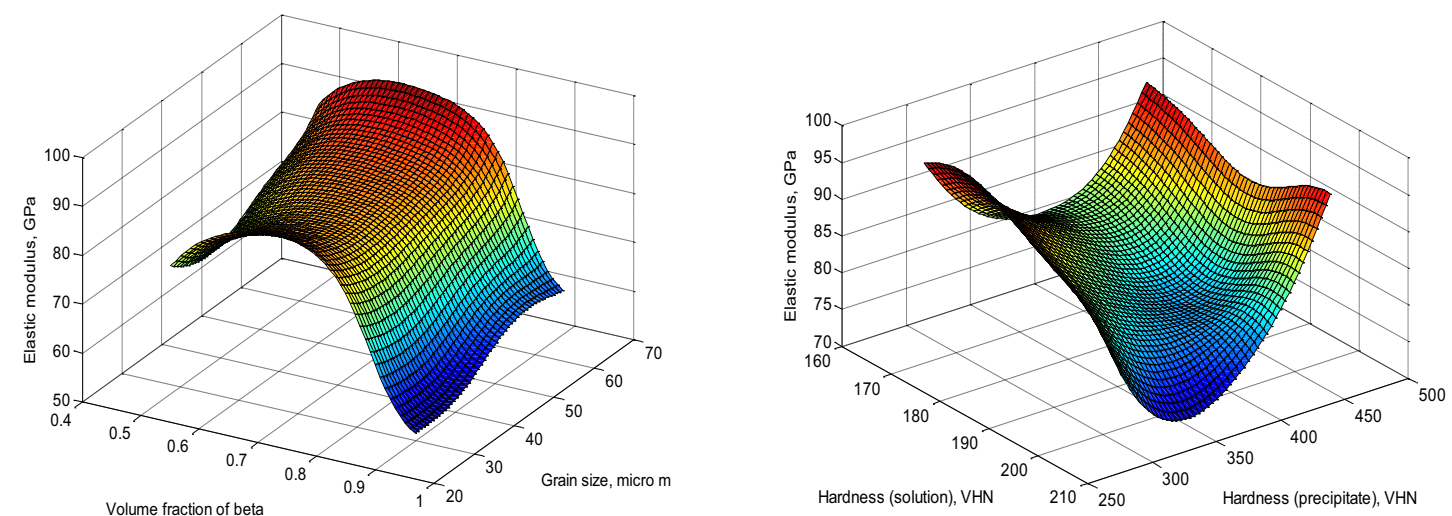

(a)

(b)

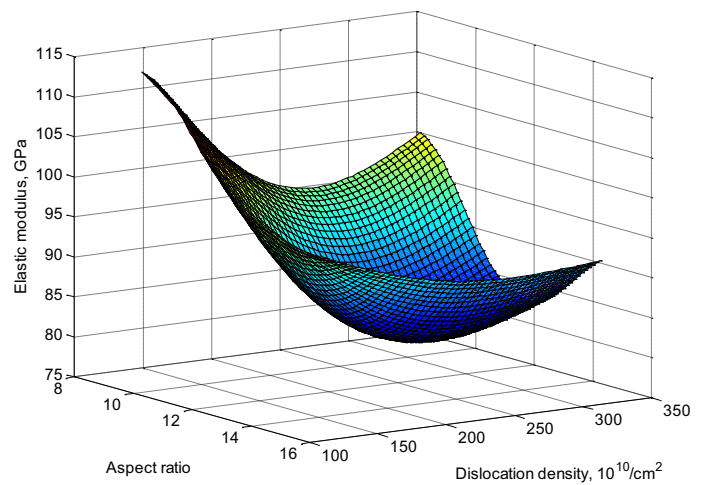

(c)

Fig. 13: Surface views generated by the FIS describing the effects of (a) volume fraction of $\beta$ and grain size, (b) solution and precipitation hardening, and (c) aspect ratio of grains and dislocation density on modulus of elasticity.

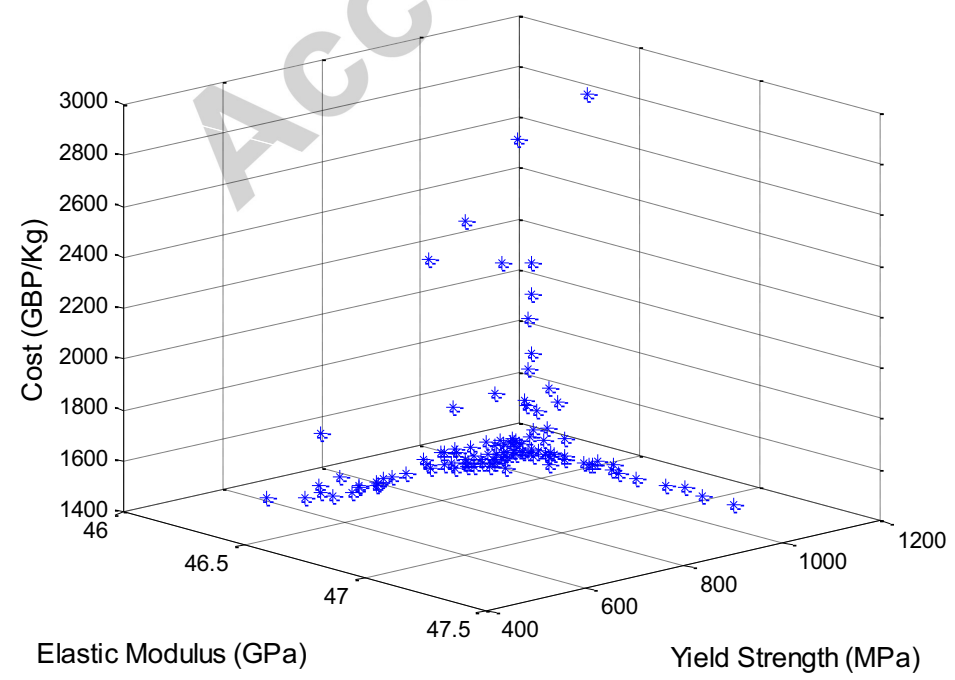


C2015. This manuscript version is made available under the CC-BY-NC-ND 4.0 license http://creativecommons.org/licenses/by-nc-nd/4.0/

Fig. 14: Pareto solutions resulted from the multi-objective optimization process.
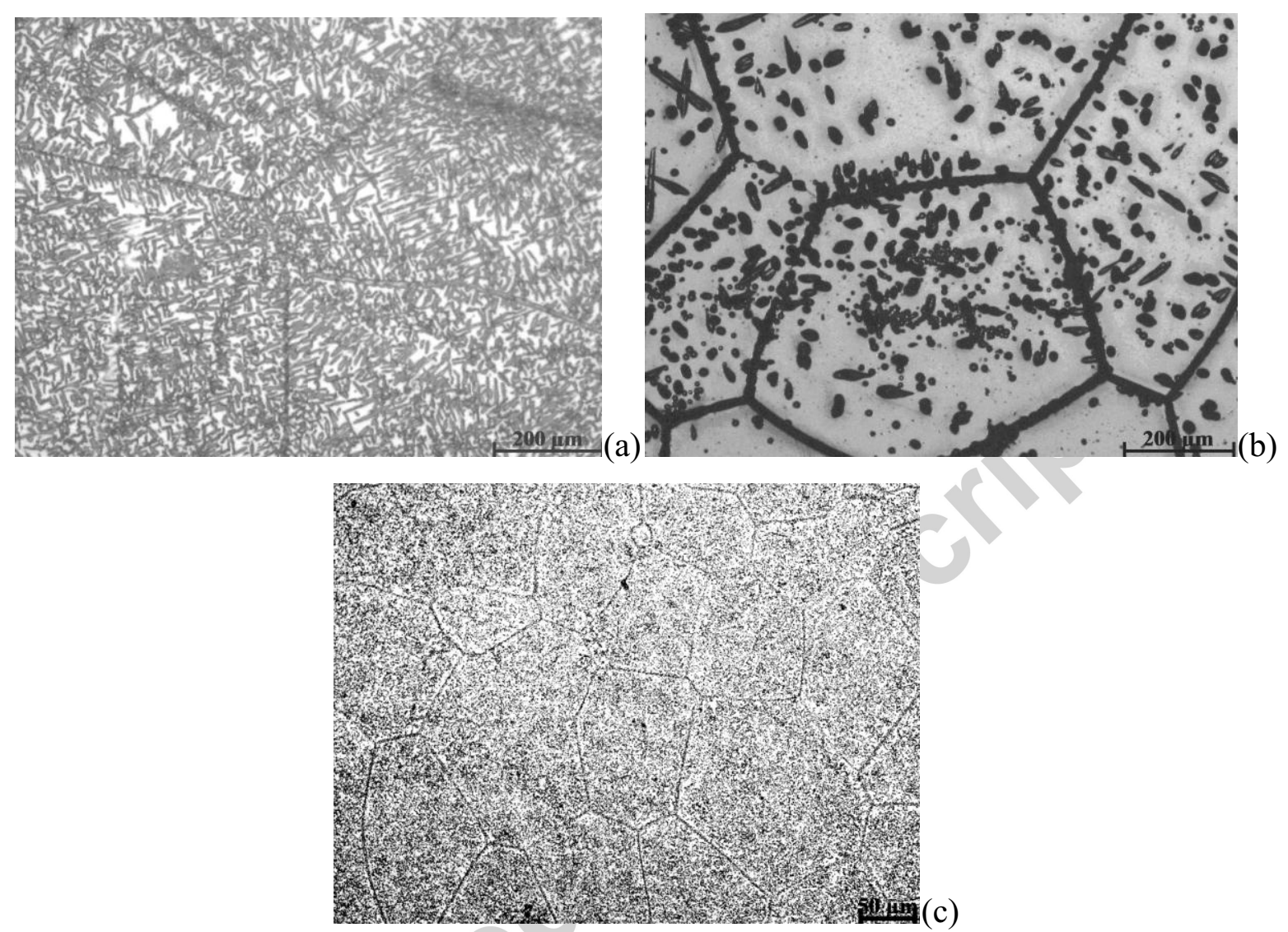

Fig. 15: Light micrographs of (a) Alloy 1, (b) Alloy 2 and (c) Alloy 3 at water quenched condition 